
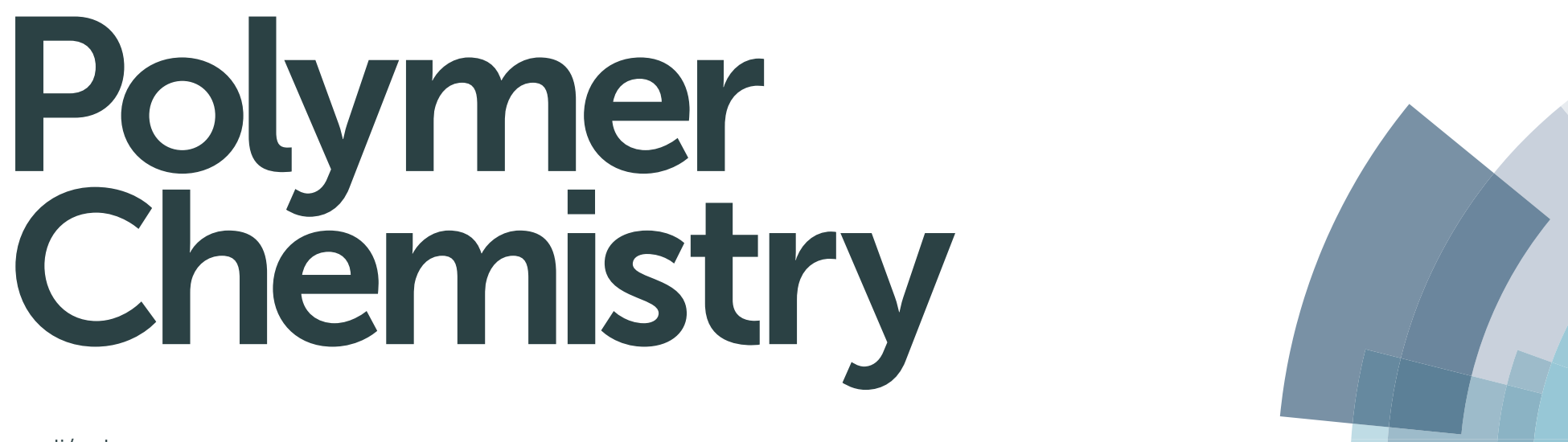

rsc.li/polymers
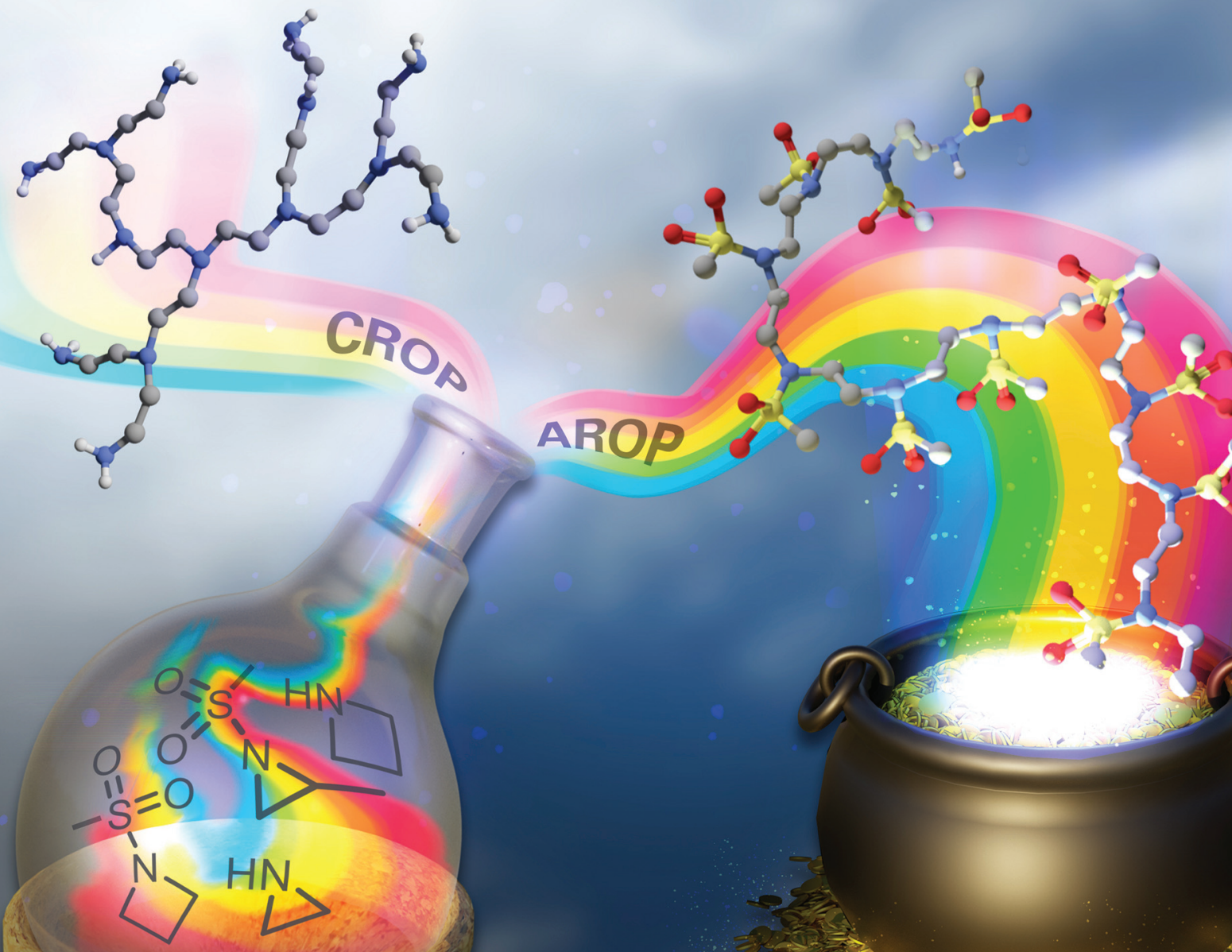

ISSN 1759-9962 


\section{D) Check for updates}

Cite this: Polym. Chem., 2019, 10, 3257

Received 19th February 2019, Accepted 3rd May 2019

DOI: 10.1039/c9py00278b rsc.li/polymers

\title{
Aziridines and azetidines: building blocks for polyamines by anionic and cationic ring-opening polymerization
}

\author{
Tassilo Gleede, ${ }^{a}$ Louis Reisman, (D) b Elisabeth Rieger, ${ }^{a}$ \\ Pierre Canisius Mbarushimana, ${ }^{b}$ Paul A. Rupar (D) *b and Frederik R. Wurm (D) *a
}

Despite the difficulties associated with controlling the polymerization of ring-strained nitrogen containing monomers, the resulting polymers have many important applications, such as antibacterial and antimicrobial coatings, $\mathrm{CO}_{2}$ adsorption, chelation and materials templating, and non-viral gene transfection. This review highlights the recent advances on the polymerizations of aziridine and azetidine. It provides an overview of the different routes to produce polyamines, from aziridine and azetidine, with various structures (i.e. branched vs. linear) and degrees of control. We summarize monomer preparation for cationic, anionic and other polymerization mechanisms. This comprehensive review on the polymerization of aziridine and azetidine monomers will provide a basis for the development of future macromolecular architectures using these relatively exotic monomers.
\end{abstract} (1)

\section{Introduction}

Despite being structural anlogs with comparable ring strain (Fig. 1), aziridine and oxirane have very different polymerization chemistries. Oxirane can be polymerized via a variety of mechanisms, including cationic ring-opening polymerization $(\mathrm{CROP})^{1}$ and anionic ring-opening polymerization (AROP) $)^{2,3}$ to form linear poly(ethylene oxide) (PEO) with high degrees of

${ }^{a}$ Max-Planck-Institut für Polymerforschung, Ackermannweg 10, 55128 Mainz, Germany.E-mail:wurm@mpip-mainz.mpg.de

${ }^{b}$ Department of Chemistry and Biochemistry, The University of Alabama, Tuscaloosa, Alabama 35487-0336, USA. E-mail: parupar@ua.edu

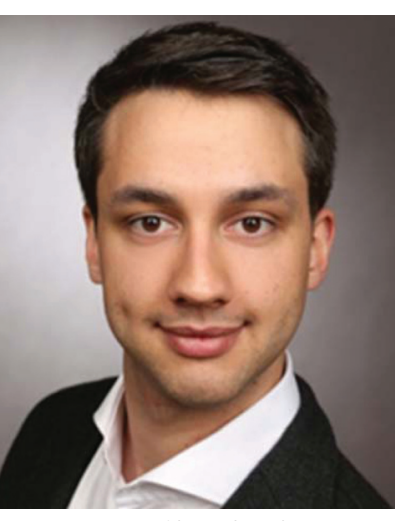

Tassilo Gleede
Tassilo Gleede studied Chemistry at the Johannes Gutenberg-Universität Mainz (Germany) and received his diploma degree in 2015 including a research stay at the Brookhaven National Laboratory, (New York, USA) developing positron emission radiotracers for human and plant studies in the group of Prof. Joanna Fowler. He joined the Max Planck Institute for Polymer research, Mainz, in the group of Dr F. R. Wurm for his PhD thesis. His research, supported by the Deutsche Forschungsgesellschaft (DFG), focuses on the living anionic polymerization of activated aziridines and their copolymerization behavior with other reactive monomers such as ethylene oxide.

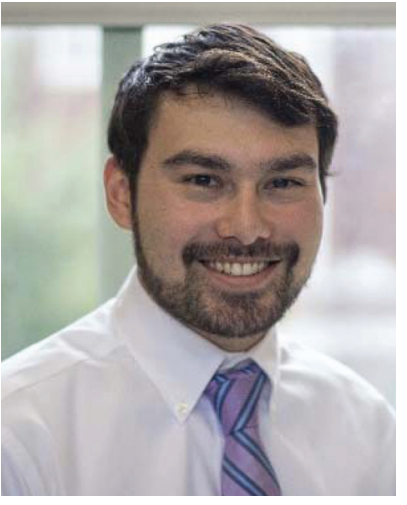

Louis Reisman
Louis "Chip" Reisman III graduated with a B.S. in Chemistry from Mercer University in 2014, where he conducted research with Prof. Adam Kiefer and Prof. Caryn Seney. He recently completed his Ph.D. at the University of Alabama under the supervision of Prof. Paul Rupar investigating the anionic ringopening polymerizations of sulfonyl-activated aziridines and azetidines. Chip will be continuing his career in chemistry by studying sustainable polymers as a postdoctoral researcher in the lab of Prof. Marc Hillmyer at the University of Minnesota. 


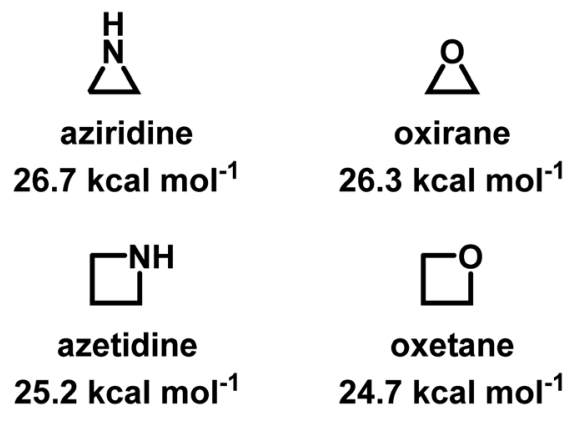

Fig. 1 Chemical structures of aziridine, azetidine, oxirane, and oxetane and their ring-strains. ${ }^{10,11}$

control. In contrast, aziridine can only polymerize via CROP to produce (hyper)branched polyethylenimine (hbPEI) with little control over molecular weight, dispersity, and microstructure. ${ }^{4-8}$ The situation is similar with azetidine (Fig. 1), the nitrogen analog of oxetane, which also only forms hyperbranched poly(trimethylenimine) (hbPTMI) via CROP. ${ }^{9}$

Even with the challenges in controlling its polymerization, the high amine density of $h b$ PEI lends its use in a wide range of applications including non-viral gene-transfection, ${ }^{7,12-44}$ anti-microbial and anti-viral coatings, ${ }^{37,45-52} \mathrm{CO}_{2}$ capture, ${ }^{53-63}$ flocculation of negatively charged fibers in paper-making industries, ${ }^{64-66}$ metal chelation in waste water treatments, ${ }^{67}$ as additives for inkjet paper production, ${ }^{16}$ as electron injection layers in organic light-emitting diodes, ${ }^{68,69}$ and materials templating. ${ }^{70}$ As such, $h b$ PEI is made industrially, initially under the commercial name Polymin, and today is marketed under the trade name Lupasol® by BASF. ${ }^{71}$ Aziridine is produced at a rate of $\sim 9000 \mathrm{t} / \mathrm{a}$ (2006), ${ }^{72}$ where, due to its toxicity, it is usually converted directly into its nontoxic intermediates and branched polymers.

The lack of control over aziridine polymerizations has significantly limited the research of linear PEI (LPEI), especially when compared to PEO and related polymers. ${ }^{6,73}$ Polyethers, especially PEO, are produced on the scale of several million tons per year and found in many everyday applications, ${ }^{74}$ while linear polyaziridines are barely used today (Fig. 2). ${ }^{75}$ This is unfortunate as the potential structural diversity of aziridines is notably greater than oxygen-containing analogs as substitution on aziridines can occur both at the carbon and nitrogen atoms of aziridine.

Use in non-viral gene-transfection has sparked renewed academic and pharmaceutical interest in PEI, especially LPEI. LPEI is attractive compared to $h b$ PEI as it can have a welldefined architecture with narrow molecular weight distributions. This makes it ideal for structure-property relationship studies and its incorporation into polymer-drug conjugates. However, since LPEI cannot be made from aziridine, it is instead synthesized indirectly via polyoxazolines. ${ }^{14}$ Typically, 2-oxazoline-based monomers, such as 2-ethyl-2-oxazoline, in the presence of cationic initiators, such as stannic chloride and boron trifluoride etherate, undergo a controlled CROP. ${ }^{76-78}$ Conversion of poly(2-oxazoline)s to LPEI can occur under acidic or alkaline conditions (Scheme 1). ${ }^{79-81}$ However, this route to LPEI has drawbacks in that the polymerization is difficult to control when targeting high degrees of polymerization and it is challenging to achieve quantitative removal of the acyl groups. ${ }^{7}$

The new appreciation for the applications of LPEI and unresolved challenges associated with azirdine polymerization means that it remains an active area of research. Since there have been no recent reviews on aziridine polymerizations (Kobayashi ${ }^{6}$ was published in 1990), we feel that such a review is warranted. This is especially true given the recent breakthroughs in the AROP of activated aziridines, which have yet to be summarized in the literature.

This review gives a comprehensive overview on the synthesis of polymers based on both aziridines and azetidines. We have chosen to include azetidines in this review as their polymerization chemistry closely mirrors that of aziridines and the

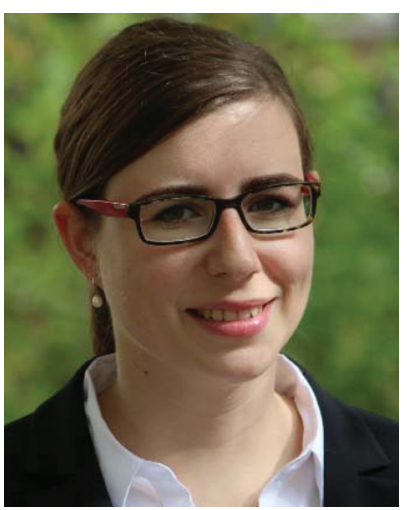

Elisabeth Rieger
Elisabeth Rieger was born in 1985 in Rosenheim (Germany). She studied biomedical chemistry at the Johannes Gutenberg - Universität Mainz (Germany), including a stay at the Brookhaven National Laboratory on Long Island (USA) in the group of Prof. Joanna Fowler. She finished her $P h D$ in the group of Dr F. R. Wurm at the Max Planck Institute for Polymer Research in Mainz in 2018. Her research focused on the sequence controlled anionic polymerization of activated aziridines monitored by real-time NMR.

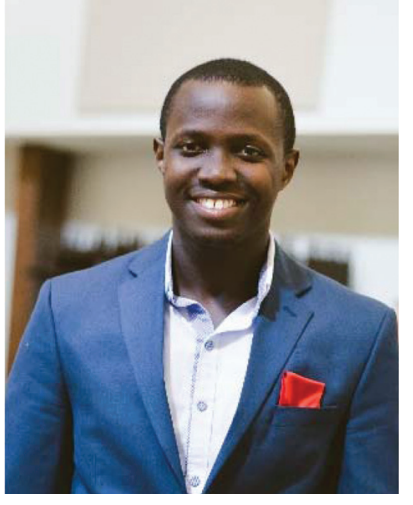

Pierre Canisius Mbarushimana studied chemistry ay Lyon College (US) and graduated with a B.Sc. degree in 2013. After that, he pursued graduate studies in analytical chemistry at the University of Alabama and completed his PhD in the Rupar group in 2018. His research interests consist of the anionic ring-opening polymerization of activated aziridines. Currently, he holds a senior scientist position at Jordi Labs in Massachusetts. 


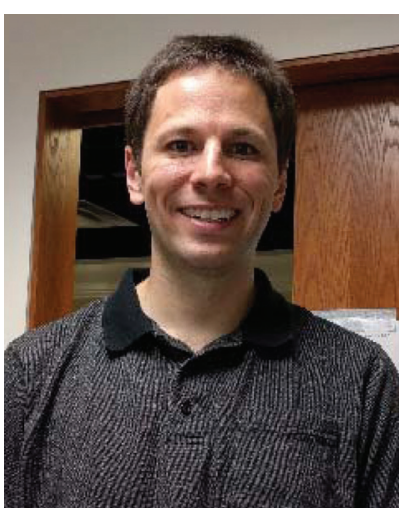

Paul A. Rupar
Paul A. Rupar completed his PhD in 2009 under the supervision of Prof. Kim Baines at the University of Western Ontario. In 2010, Paul started as a NSERC Postdoctoral Researcher at the University of Bristol in the group of Prof. Ian Manners where he investigated the self-assembly of polymer nanoparticles. In 2011, Paul was a Marie Curie Postdoctoral researcher, also in the Manners group. Paul is currently an Assistant Professor in the Department of Chemistry \& Biochemistry at the University of Alabama. His current research interests span from conjugated inorganic systems to the anionic polymerization of aziridines and azetidines. conclude with routes to aziridine and azetidine copolymers and highlight the possibilities for functionalization or preparation of various polyamine structures. Spaced through the review are summaries of the synthetic methods to synthesize the aziridine and azetidine monomers. Detailed analysis of the literature on gene-transfection can be found elsewhere. ${ }^{84}$ This review will

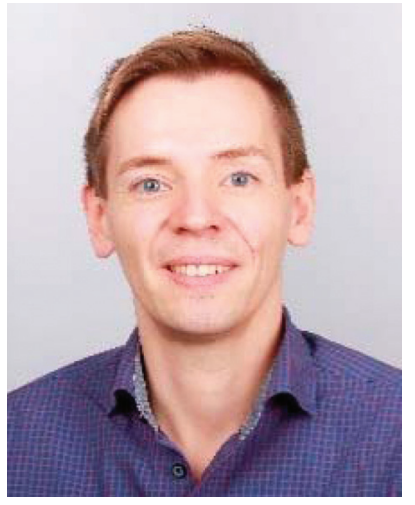

Frederik R. Wurm
Frederik $R$. Wurm received his PhD in 2009 from the Johannes Gutenberg-Universität Mainz (Germany) working on nonlinear block copolymers. From 2009 to 2011 he was a postdoctoral Humboldt fellow at EPFL (Switzerland) focusing on novel bioconjugation strategies. In 2012, he joined the Max Planck Institute for Polymer Research (Germany). Frederik has published over 150 research articles and received several awards, including the Polymer Chemistry Lectureship. Frederik leads the research group "Functional Polymers" and develops new degradable and molecularly adjustable polymers. He is particularly interested in biodegradable polyphosphoesters. Additionally, his research covers areas of biopolymer modification and sequencecontrolled polymerization, focusing on living anionic polymerization. 
1)

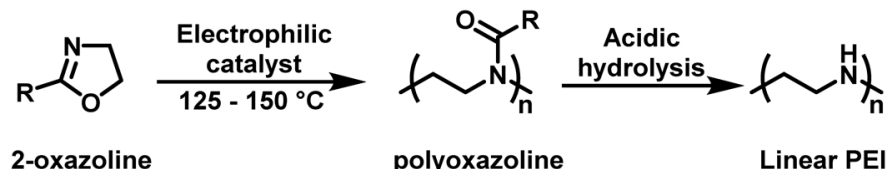

2)

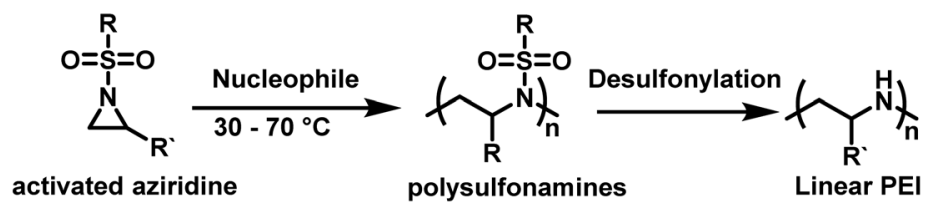

Scheme 1 (1) Synthesis of linear polyethylenimine (LPEI) from 2-oxazoline by cationic ring-opening polymerization in comparison to (2) anionic ring-opening polymerization of sulfonyl aziridines as an alternative pathway to linear PEI derivatives. ${ }^{82,83}$

also not cover oxazoline polymerization chemistry; the interested reader is encouraged to consult recent reviews. ${ }^{85-87}$

\section{Cationic ring-opening polymerization of aziridines and azetidines}

The differences in polymerization chemistry between nitrogen and oxygen containing strained heterocycles arise due to the reduced electronegativity of nitrogen, the presence of an acidic hydrogen atom on the nitrogen atom, and the increased nucleophilicity of the lone-pair of electrons on nitrogen. The decreased electronegativity of nitrogen prevents the nucleophilic ring-opening of aziridine and azetidine in AROP and increases the nucleophilicity of the lone pair electrons on nitrogen, leading to branching and loss of control in CROP. In addition, use of very basic nucleophiles simply deprotonates the secondary amine in aziridine and azetidine rather than inducing ring-opening. Therefore, the majority of aziridine and azetidine polymerizations proceed through a cationic mechanism.

\subsection{Cationic ring-opening polymerization of aziridine}

The cationic polymerization of aziridine and related cyclic amines were recorded in the patent literature as early as $1937 .^{88}$ However, the nature of the polymerization and the structure of the resulting polymer was first thoroughly explored by Jones and coworkers in $1944 .^{89}$ Numerous studies have been performed, elaborating on this work, resulting in the mechanism, depicted in Scheme $2 .^{5}$ Polymerization is initiated by electrophilic addition of an acidic catalyst to aziridine to form an aziridinium cation. An additional aziridine monomer, acting as a nucleophile, ring opens the active aziridinium ion resulting in the formation of a primary amine and a new aziridinium moiety. Subsequent aziridines attack the propagating aziridinium terminus, resulting in the linear propagation of the polymer chain. However, as the secondary amine groups in the developing polymer chain are also nucleophilic, they also ring open aziridinium species leading to branching and results in $h b$ PEI. For $h b$ PEI synthesized in solution, this leads to

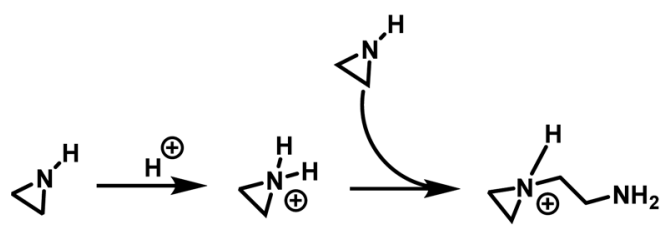

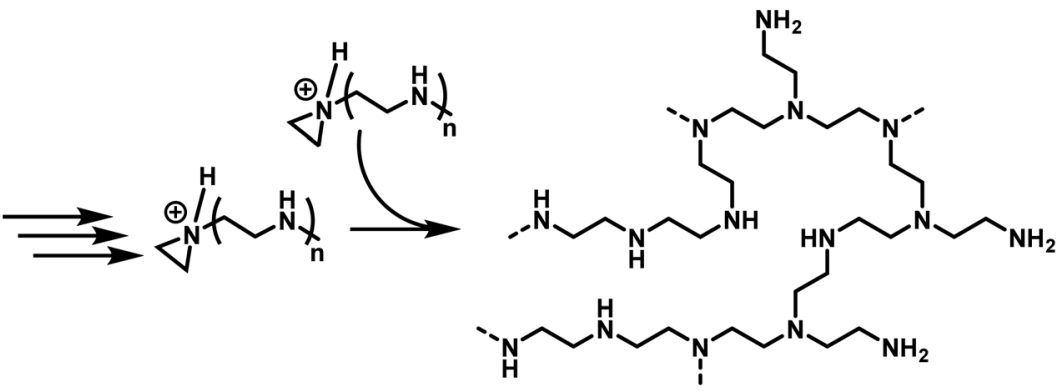

Scheme 2 Mechanism of the cationic ring-opening polymerization of aziridine, leading to $h b P E l$. 
a ratio of primary: secondary : tertiary amines of $1: 2: 1$ (determined by ${ }^{13} \mathrm{C}$ NMR). ${ }^{90}$ This ratio can be varied depending upon the reaction conditions and the molar mass of the polymer (i.e. lower molar mass $h b \mathrm{PEI}$ has more primary amines). ${ }^{90}$

The polymerization of aziridine is likely more complex than that depicted in Scheme 2. Barb and coworkers ${ }^{91}$ studied the kinetics and mechanism of the polymerization of ethylenimine in the presence of different catalysts, such as $p$-toluenesulfonic acid, benzoic acid and others. They noted that the polymerization proceeds much like a step-growth polymerization, and that aziridine dimer is the dominate species early in the polymerization. A recent study on the polymerization of azetidine reached similar conclusion ( $c f$. section 2.5). ${ }^{8}$ Furthermore, they noted an increase in molar masses in polymerization mixtures containing no monomeric species. This suggests that both monomer and polymer molecules are capable of activation and deactivation, thus making it more difficult to control the molecular weight and architecture of the resulting $h b$ PEI.

\subsection{Cationic ring-opening polymerization of 2-substituted aziridines}

In general, the CROP of 2-substituted aziridines proceeds similarly to the parent aziridine. 2-Methylaziridine, or propylene imine, was reported to undergo polymerization initiated by $\mathrm{BF}_{3} \mathrm{Et}_{2} \mathrm{O} .^{92}$ The resulting polypropylenimine appeared as a viscous oil insoluble in water but soluble in $\mathrm{CHCl}_{3}$ and DMSO. The structure of polypropylenimine formed from the cationic polymerization of 2-methylaziridine has been determined to be highly branched, similarly to $h b$ PEI formed from the CROP of aziridine. A photoinitiated cationic polymerization of 2-methylaziridine has also been reported. ${ }^{93}$ Regardless of the initiator used, the polymerization of 2-methylaziridine suffers from termination. This is due to nucleophilic addition of a tertiary amine within the polymer to an aziridinium, resulting in the formation of an unreactive quaternary amine.

CROP of 2-phenylaziridine, initiated by methyl triflate, perchloric acid, $\mathrm{BF}_{3} \mathrm{Et}_{2} \mathrm{O}$, dimethyl sulfate or hydrochloric acid, was found to form only low molecular weight polymers of $\leq 3000 \mathrm{~g} \mathrm{~mol}^{-1} \cdot{ }^{94}$ These polymerizations did not result in full monomer consumption due to high rates of termination. Although the polymerization occurred at a much slower rate, Bakloutl and coworkers found that employing methyl triflate as initiator led to the formation of the highest molecular weight polymers of $2500-3000 \mathrm{~g} \mathrm{~mol}^{-1}$. Further investigation by studying the kinetics revealed this was due to an increase in the ratio of the propagation rate constant to the termination rate constant. It was proposed that this was due to the triflate counter ion stabilizing the aziridinium ion better than the counter ions of the other initiators.

\subsection{Monomer preparation for cationic polymerization of 2-substituted aziridines}

A pioneering approach to aziridines is the " $\beta$-chloroethylamine process", which uses vicinal chloro amine hydrochloride salts and sodium hydroxide. As corrosive hydrochloric acid ( $\mathrm{HCl}$ ) is released during the reaction, which could also lead to a CROP

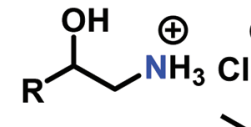<smiles>[R]C(Cl)CCl</smiles>
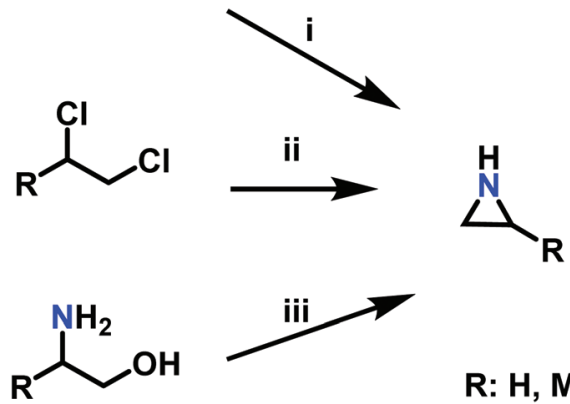

R: H, Me

Scheme 3 Synthesis of aziridines with and without a ring substituent (R) by i: the $\beta$-chloroethylamine process, ii: the Dow Process, iii: the Wenker synthesis.

of aziridine, this process lost industrial relevance in 1963 (Scheme 3i). ${ }^{72}$ The "Dow Process" (Scheme 3ii) was used on the industrial scale beginning in 1978, but was stopped due to the drawbacks of high corrosion rates to reactors and waste stream disposal. Per one equivalent starting material, three equivalents of ammonia are necessary, which gives the Dow Process a low atom economy. ${ }^{72}$ Today, aziridine is prepared via the "Wenker synthesis" (Scheme 3iii). This two-step process starts with the reaction of 2-aminoethanol, or other vicinal amino alcohols, with sulfuric or chlorosulfuric acid. The sulfates are treated with 5 eq. sodium hydroxide or saturated sodium carbonate solution to give the aziridine after a nucleophilic cyclization with 2-step yields of $\sim 90 \% .^{72}$ Significant waste disposal problems are avoided through high atom economy and nontoxic side products. $^{95}$ For laboratory scales, sulfates can be purified by filtration and washing with excess ether. Low molecular weight aziridines such as 2-methyl aziridine can be further purified by steam distillation. If stored longer, alkali hydroxide stabilizes aziridine against spontaneous cationic polymerization. $\mathrm{N}$-Substituted aziridines can also be obtained if secondary amines are used as starting material. ${ }^{95-97}$

\subsection{The cationic ring-opening polymerization of $\mathrm{N}$-substituted aziridines}

The ring-opening polymerization of $\mathrm{N}$-substituted aziridines typically proceeds via a cationic mechanism. The details of the polymerization of $\mathrm{N}$-substituted aziridines is like that of aziridine, with one important distinction: the possibility of an irreversible termination reaction. ${ }^{5}$ Termination occurs due to the (inter and intramolecular) nucleophilic attack of tertiary amines on aziridinium moieties, which results in the formation of unreactive, non-strained quaternary ammonium salts (Scheme 4).

As such, the polymerizations of simple $N$-substituted aziridines, often proceed only to low conversions $(<55 \%){ }^{5}$ This is exemplified by the fact that in acetone the reaction of allyl bromide with 9-fold excess of $N$-( $n$-butyl)aziridine produces the piperazinium cation in a $96 \%$ yield with excess aziridine being recovered (Scheme 5). ${ }^{98}$ 


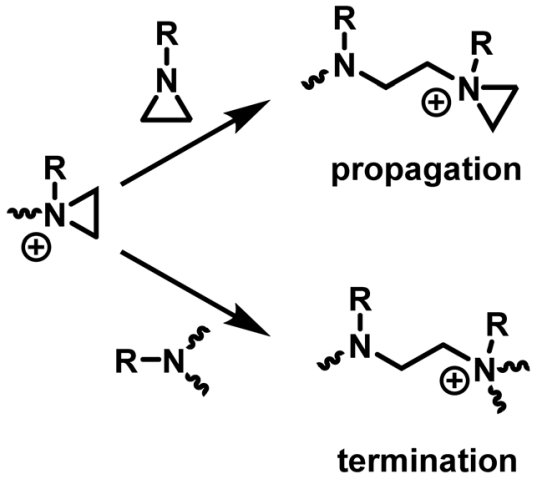

Scheme 4 Competition between propagation and termination reactions during the CROP of $N$-substituted aziridines.

Goethals performed a series of detailed studies on the polymerization of $\mathrm{N}$-alkylaziridines primarily focusing on the kinetics of the polymerization. ${ }^{5}$ A key focus of this study was to measure the propagation rate constants $\left(k_{\mathrm{p}}\right) v s$. the rates of termination $\left(k_{\mathrm{t}}\right)$. Employing $\mathrm{Et}_{3} \mathrm{OBF}_{4}$ as a Lewis acid, due to its rapid initiation, Goethals found that alkyl substituents with low steric bulk tended to have low $k_{\mathrm{p}} / k_{\mathrm{t}}$ ratios, which leads to the polymerizations proceeding to only low conversion. For instance, $N$-ethylaziridine has a $k_{\mathrm{p}} / k_{\mathrm{t}}$ of 6 while the $k_{\mathrm{p}} / k_{\mathrm{t}}$ for $N$-isopropylaziridine was 21 . In contrast, $N$-tertbutylaziridine polymerized with essentially no termination $\left(k_{\mathrm{p}} / k_{\mathrm{t}} \approx \infty\right)$ and no transfer reactions, thus allowing the polymerization to be living-like. The introduction of a methyl group in the 2-position of $\mathrm{N}$-alkylaziridines was found to greatly reduce the rate of termination relative to propagation. For example, the polymerization of $N$-benzyl aziridine stops at very low conversion due to termination $\left(k_{\mathrm{p}} / k_{\mathrm{t}}=85\right)$, while $N$-benzyl-2-methylaziridine polymerizes with almost no termination $\left(k_{\mathrm{p}} / k_{\mathrm{t}}=1100\right)$ (Fig. 3$)$.

While substitution in the 2-position greatly increases the $k_{\mathrm{p}} / k_{\mathrm{t}}$ ratio, geminal substitution at the 2-position completely inhibits the polymerization. Specifically, $N$-benzyl-2,2-dimethylaziridine was only found to form $\mathrm{N}$-benzyl- $\mathrm{N}$-ethyl-2,2dimethylaziridinium when reacted with $\mathrm{Et}_{3} \mathrm{OBF}_{4}{ }^{5}$ Interestingly, $N$-benzyl- $N$-ethyl-2,2-dimethylaziridinium could initiate the polymerization of $N$-benzylaziridine (Scheme 6).

Goethals also reported on the CROP of neat $\mathrm{N}$-(2-tetrahydropyranyl)aziridine initiated by Lewis acids (Scheme 7). ${ }^{99}$ This polymerization also appears to proceed without termination due to the bulky tetrahydropyranyl substituent. Hydrolysis of the polymer produced from $N$-(2-tetrahydropyranyl)aziridine in dilute $\mathrm{HCl}$, followed by neutralization with $\mathrm{NaOH}$, resulted in the formation of high molecular weight linear PEI (LPEI).
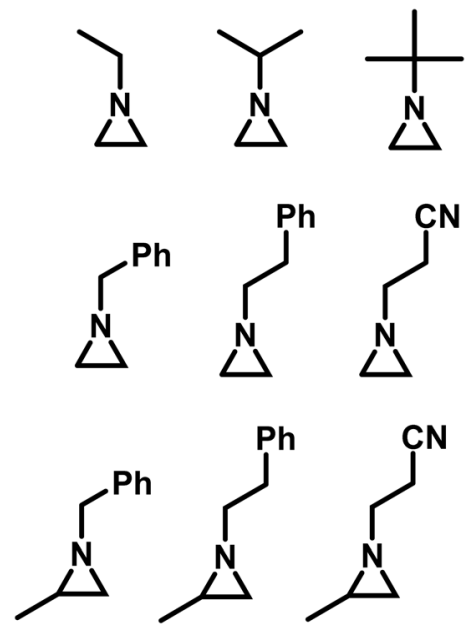

Fig. $3 N$-Alkyl aziridines that undergo CROP. ${ }^{5}$

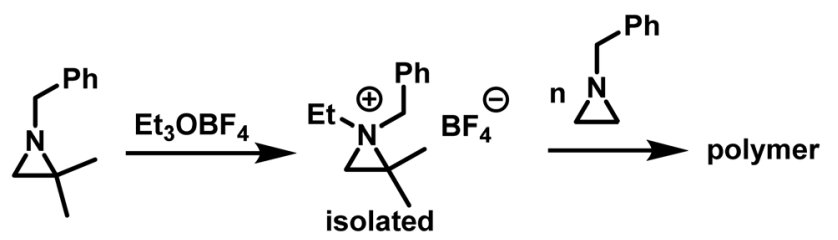

Scheme 6 Formation of $N$-benzyl- $N$-ethyl-2,2-dimethylaziridinium and polymerization according to ref. 5 .

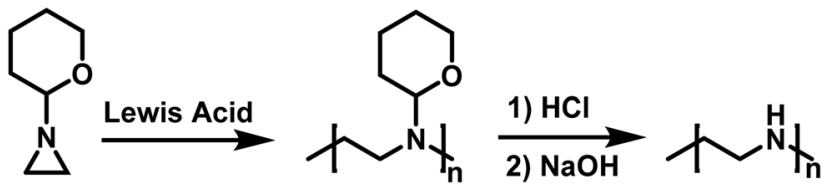

Scheme 7 Polymerization of $\mathrm{N}$-(2-tetrahydropyranyl)aziridine in route to LPEl according to ref. 99.

$M_{\mathrm{w}}$ for the LPEI, as determined by LALLS, was as high as $19.6 \mathrm{~kg} \mathrm{~mol}{ }^{-1}$, which is the highest molecular weight LPEI produced from an aziridine to date.

Polymerization of $\mathrm{N}$-(2-hydroxyethyl)aziridine has also been reported to occur via traditional Lewis acid catalysts and also through electroinitated polymerization. ${ }^{100}$ The resulting poly ( $N$-(2-hydroxyethyl)aziridine) (PHEA) has been shown to be an excellent chelator of metal cations. By simple adjustment of $\mathrm{pH}$, PHEA can selectively remove various metals. ${ }^{101}$ At $\mathrm{pH}=3$, PHEA can remove $\mathrm{Cu}(\mathrm{II})$ from solution with as high as $99.5 \%$ reten-

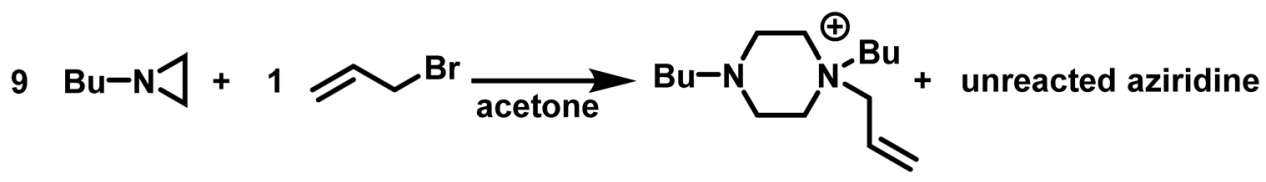

Scheme 5 Reaction of $N$-(n-butyl)aziridine to form a piperazinium with no detectable polymerization. 


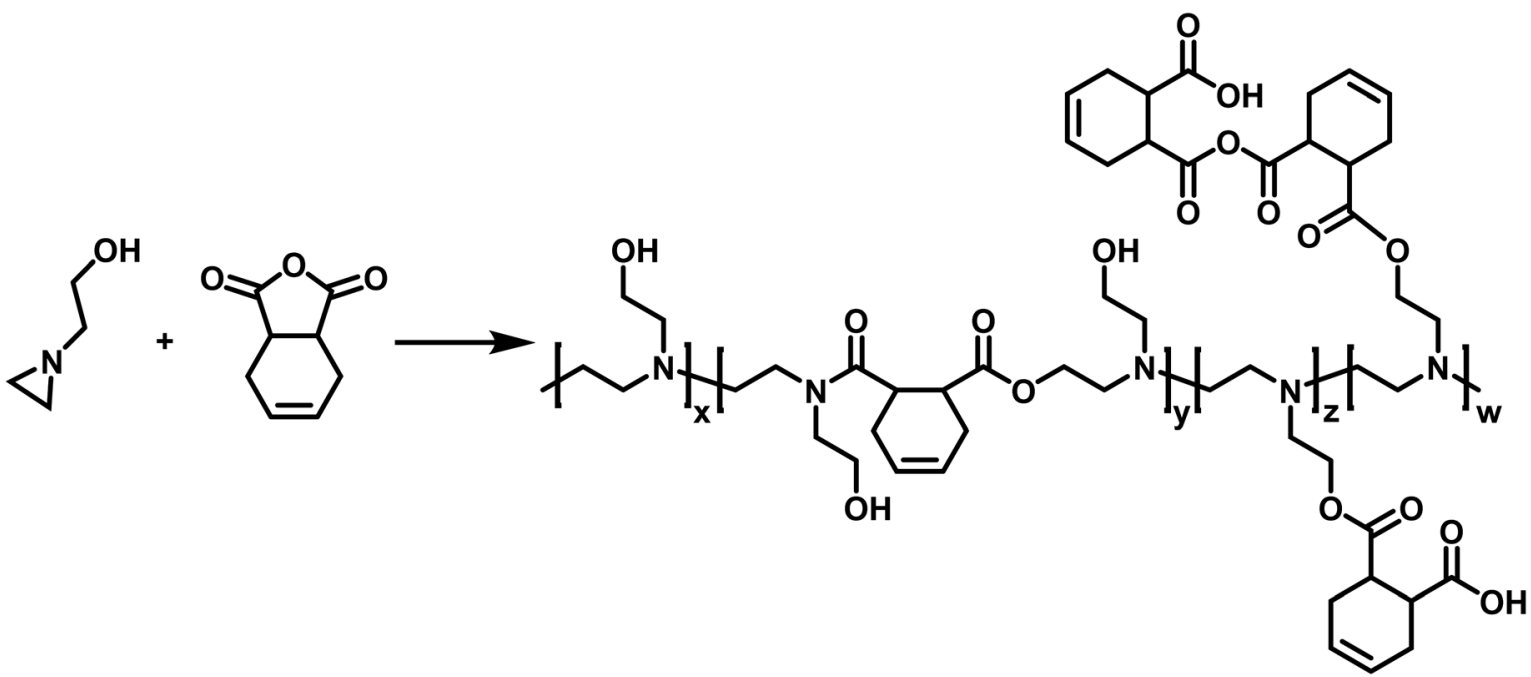

Scheme 8 Copolymerization of N-(2-hydroxyethyl)aziridine with THPhA according to ref. 102.

tion. With neutral pH, Co(II), Cr(III), Fe(III), Ni(II), Zn(II), and Cd(II) can be removed from solution at as high as $99.5 \%$. These results are similar to those of $h b \mathrm{PEI}$, with the exception of $\mathrm{Cr}$ (III) at neutral pH, when PHEA is a much stronger chelator.

CROP of aziridines have also been employed in the synthesis of copolymers. Utilizing $N$-(2-hydroxyethyl)aziridine, Pooley and coworkers synthesized a copolymer with 1,2,3,6tetrahydropthalic anhydride (THPhA) (Scheme 8). ${ }^{102}$ This polymerization was accomplished in the absence of an initiator. These polymers are formed by employing a nucleophilic monomer with an electrophilic comonomer. These monomers form a zwitterion which leads to initiation and propagation in the polymerization. Pooley extended this work with $\mathrm{N}$-(2-hydroxyethyl)aziridine to produce copolymers with a library of other electrophilic monomers. ${ }^{103-109}$

Although not present in the open literature, there are reports in the patent literature on the CROP of sulfonylaziridines. ${ }^{110}$ These polymerizations were performed neat by melting the monomers and were performed in the presence of Lewis acids such as $\mathrm{AlCl}_{3}, \mathrm{FeCl}_{3}$, and $\mathrm{ZnCl}_{2}$. Employing different monomer:catalyst feeds from 200:1 to 10000:1 polymers were obtained, but no further characterization details were given. ${ }^{110}$

\subsection{Cationic ring-opening polymerization of azetidines}

While the polymerization of aziridines has been studied, there are significantly fewer examples of the four-membered ring, azetidine, in the literature. Unsurprisingly, most of this work on the polymerization of azetidines focuses on the polymerization of $N$-substituted azetidines. ${ }^{4,111-115}$ While the first polymerization of an azetidine ring was reported by Kornfeld, in 1960, regarding the polymerization of conidine, ${ }^{113}$ Goethals provided the greatest contributions to the field due to his studies of multiple azetidines. ${ }^{4,5,99,115-118}$

In 1974, Goethals reported of the polymerization of unsubstituted azetidine (Scheme 9). ${ }^{4}$ The polymerization proceeded via a cationic mechanism, similar to the CROP of aziridine, to form hyperbranched poly(trimethylenimine) ( $h b$ PTMI). ${ }^{5,6}$ This study found that after $8 \mathrm{~h}$ at $70{ }^{\circ} \mathrm{C}$ in methanol nearly all monomer had been consumed. Interestingly, it was found that when all the monomer had been consumed, $70 \%$ of the reaction mixture consisted of dimer. This is explained by the $\mathrm{p} K_{\mathrm{B}}$ difference of azetidine and $N$-methylazetidine. The $\mathrm{p} K_{\mathrm{B}}$ of azetidine is 11.29 (ref. 115) and 10.40 (ref. 119) for $N$-methylazetidine. Due to the differences in basicity, and the similarity in structure of the azetidine dimer to $N$-methylazetidine, it is expected that a proton would transfer from the protonated tertiary amine to the more basic monomer. Because of preferential formation of dimer to propagation it was hypothesized that the resulting polymer should contain many primary and tertiary amines, rather than exclusively producing secondary amines. This can be explained by two possible reaction pathways. Propagation only occurs once the tertiary amine in the dimer is protonated. The cyclic ammonium salt can then be opened by nucleophilic addition of either a primary amine or a tertiary amine. If propagation occurred by only addition of primary amines the expected polymer would contain only secondary amines. If propagation occurred by only addition of tertiary amines the expected polymer would contain equal numbers of primary and tertiary amines but no secondary amines. ${ }^{1} \mathrm{H}$ NMR spectroscopy revealed that the PTMI produced contained $20 \%$ primary, $60 \%$ secondary, and $20 \%$ tertiary amines, suggesting that both mechanisms are occurring. However, tertiary amines may also be formed by the addition of secondary amines along the backbone of the polymer to the cyclic ammonium salt. Similarly, a tertiary amine along the backbone of the polymer could add to a cyclic ammonium salt. However, this is less probable due to the lower basicity of a tertiary amine to a secondary amine. ${ }^{120}$ Additionally, this reaction would lead to chain termination. Goethals determined in this work, by monitoring the increase in molecular weight over time, that this termination must be very slow, if occurring at all. 


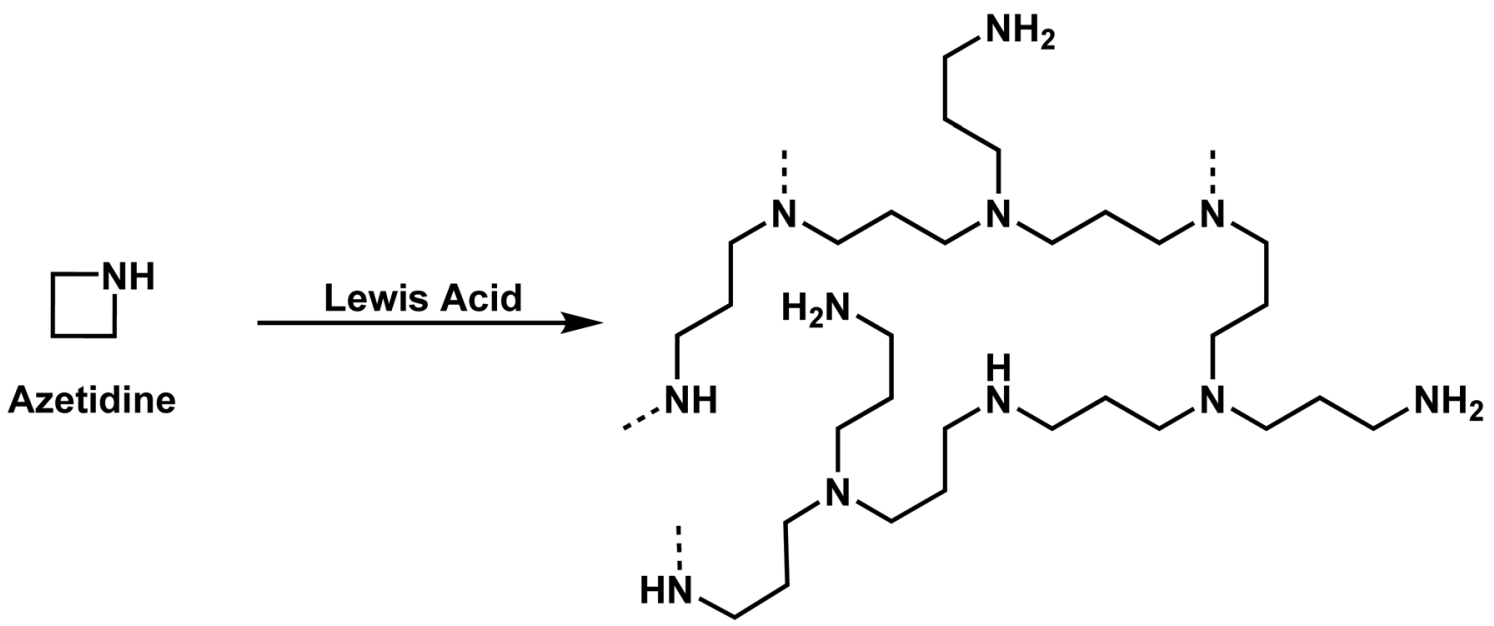

\section{hbPTMI}

Scheme 9 The cationic ring-opening polymerization of azetidine to produce hyperbranched PTMI (hbPTMI).

In 2017, Goethals' initial work on the polymerization of unsubstituted azetidine was confirmed by Sarazen and Jones. ${ }^{8}$ They provided a report of the cationic polymerization of azetidine, which was impregnated onto a silica scaffold. These porous materials were then employed in the capturing of $\mathrm{CO}_{2}$, which is a promising preliminary application of PTMI.

\subsection{Cationic ring-opening polymerization of substituted azetidines}

Goethal's work was not limited to unsubstituted azetidines. $\mathrm{He}$ also reported the polymerization of 1,3,3-trimethylazetidine. $^{4,115}$ In this work, Goethals studied the CROP of 1,3,3-trimethylazetidine. After initially screening multiple solvents and initiators, the kinetics of the polymerization were studied in nitrobenzene employing $\mathrm{Et}_{3} \mathrm{OBF}_{4}$ as the initiator at temperatures $>60^{\circ} \mathrm{C}$.

The CROP of 1,3,3-trimethylazetidine is first-order with respect to monomer concentration and the number of active chain ends remains constant throughout the polymerization with a propagation rate constant, $k_{\mathrm{p}}$, of $1.2 \times 10^{-4} \mathrm{~L} /(\mathrm{mol} \mathrm{s})^{-1}$ at $78{ }^{\circ} \mathrm{C}$ in nitrobenzene, making the polymerization notably slow. Additionally, molecular weights increased linearly with increase in the monomer to initiator ratio when studied using vapor pressure osmometry. This data, coupled with studies showing that initiation is significantly faster than propagation, suggests that the polymerization displays living character. Indeed, upon a second addition of monomer, following complete consumption of the initial monomer concentration, molecular weight increased following the same rate as the initial polymerization, confirming this hypothesis. This contrasts from other heterocyclic CROP, such as oxetanes, ${ }^{121}$ thietanes, ${ }^{122}$ and selenetanes ${ }^{123}$ in which the polymerizations either slowed or stopped at low conversions. This is attributed to the reaction of the heteroatoms in the polymer backbone to the growing chain end, producing unstrained, unreactive cations. It is suggested that the polymerization of 1,3,3-tri- methylazetidine is living due to the increased basicity of 1,3,3trimethylazetidine compared to the tertiary amines contained in the polymer backbone. ${ }^{120}$

Goethals further studied the polymerization kinetics of 1,3,3-trimethylazetidine in nitrobenzene employing $\mathrm{Et}_{3} \mathrm{OBF}_{4}$ as the initiator by varying the polymerization temperature and monomer to initiator ratio. In varying the temperature, an Arrhenius plot was also constructed and the activation energy of 1,3,3-trimethylazetidine was found to be $19 \mathrm{kcal} \mathrm{mol}^{-1}$. Additionally, in varying the monomer to initiator ratio, little deviation was found in the value of $k_{\mathrm{p}}$, suggesting the reaction is first order with respect to initiator, $\mathrm{Et}_{3} \mathrm{OBF}_{4}$.

\section{Anionic polymerization of aziridines}

Recently, a number of researchers have been interested in the newly established anionic polymerization of $\mathrm{N}$-activated aziridines to prepare linear polyaziridines. In contrast to cationic polymerization, anionic polymerization uses nucleophilic initiators and propagates through an anionic chain end. Anionic polymerizations are attractive due to the high degree of control over molecular weight and dispersity of the resulting polymers compared to other polymerization methods.

The first anionic polymerization of an aziridine, via an azaanion was reported by Bergman and Toste in 2005. ${ }^{124}$ When investigating the reactivity of a nucleophilic transition metal complex, Bergman, Toste, and coworkers unexpectedly observed ring-opening polymerization of enantiopure $(+)-2-$ benzyl- $N$-tosylaziridine to form a poly(sulfonylazirdine). ${ }^{124}$ This molecule is activated at the ring-nitrogen by an electronwithdrawing sulfonyl group, enabling nucleophilic attack at the aziridine ring in the 3-position. The electron withdrawing effect of the sulfonyl group further stabilizes the evolving azaanion at the growing chain end by delocalization, and propagation continues via sulfonamide anions (Scheme 10). 

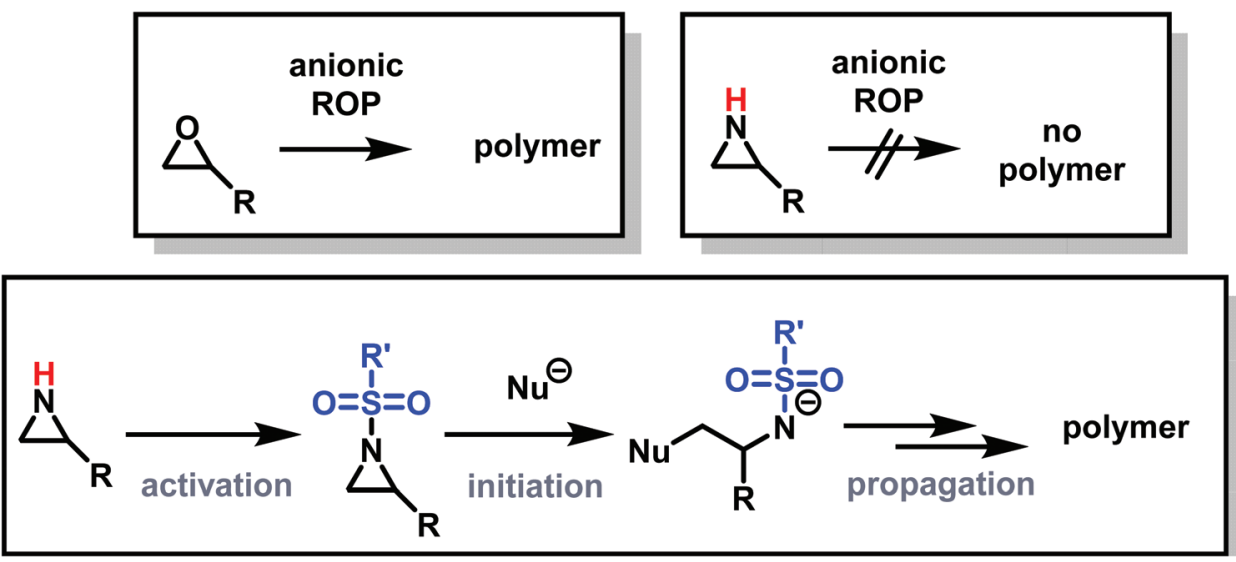

Scheme 10 Top: Established anionic ring-opening polymerization of epoxides vs. no anionic ring-opening polymerization of aziridines. Bottom: Activation strategy of aziridines to sulfonyl-aziridines, allowing for anionic ring-opening polymerization.

Different activating groups have also been investigated for the anionic polymerization of aziridines. Examples include diphenylphosphinyl, acetyl, and ethylcarbamoyl substituents, but exclusively the sulfonamide-aziridines were suitable for azaanionic polymerization to date. ${ }^{124}$

\subsection{Preparation of sulfonyl aziridines for anionic polymerizations}

Since anionic polymerization does not tolerate acidic protons, the aziridine $\mathrm{N}-\mathrm{H}$ needs to be substituted with electron-withdrawing sulfonyl groups, i.e. "activation groups" (Scheme 11). In analogy to the Hinsberg reaction, ${ }^{125}$ secondary amines react with sulfonyl chlorides to produce the respective sulfonyl aziridines. Xu et $a l^{126}$ presented an efficient microwave-assisted one-pot reaction of valinol, L-phenylalaninol, L-leucinol, L-alaninol and L-serine methylester, along with methyl-, phenyl-, and 4-methoxyphenyl-sulfonic chlorides to yield sulfonyl aziridines. Potential solvents for this strategy were diethyl ether, THF, acetonitrile, and dichloromethane. Bases such as alkali carbonates and hydroxides are used with DMAP as catalyst. In 30 minutes Xu et al. were able to prepare different sulfonyl aziridines with high yields of $84 \%-93 \%$.

Amino acids have also been used to produce $N$-tosylaziridines in a three-step process (Scheme 12). ${ }^{127}$ This was achieved by the $N$-tosylation of the amino acid, followed by reduction of the carboxylic acid to yield $\mathrm{N}$-tosyl-2-amino alcohols and finally $O$-tosylation with an in situ ring-closing. Particularly interesting is that this method does not require any purification of intermediates.

Aziridination of olefins (route (vi) in Scheme 11) was also utilized to produce sulfonyl aziridines. Sulfonyl aziridines with varying lengths of alkyl chains were produced in a single step that is tolerant to functional side groups, such as alcohols and acetals. An important advantage of this strategy is that toxic aziridine is avoided and the activated sulfonyl aziridines are obtained directly. This route employing non-functionalized alkenes to produce sulfonyl aziridines has high yields of 95\% with rhodium catalysts and up to $93 \%$ with PTAB as catalyst,
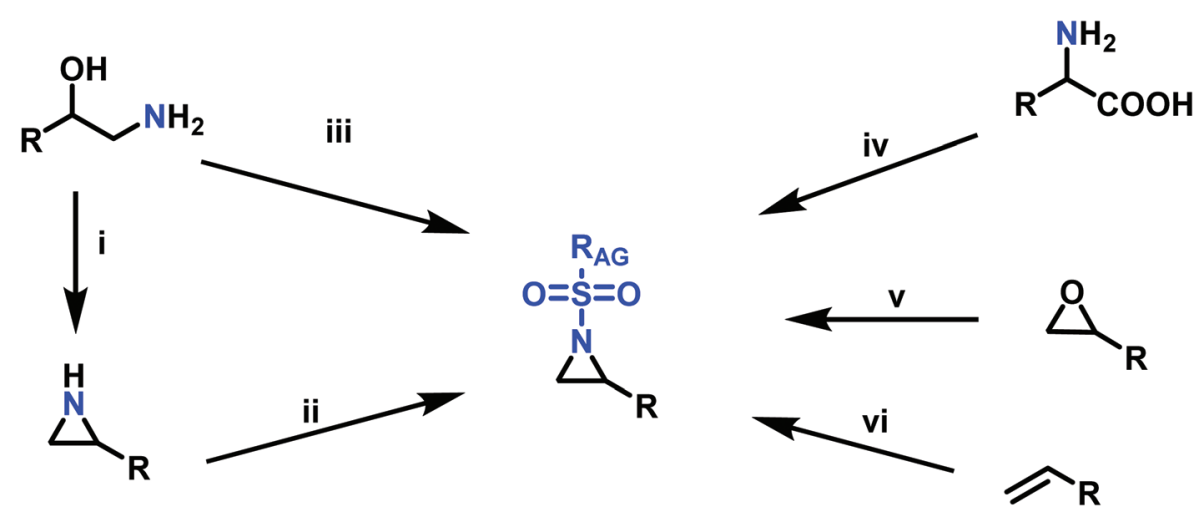

Scheme 11 Synthesis of aziridine monomers for the azaanionic polymerization: i: Wenker synthesis of aziridine: (1) vicinal amino alcohol derivate, sulfuric acid or sulfuric acid chloride (2) $\mathrm{NaOH}$ (aq.); ii: sulfonyl chloride, TEA, DCM; iii: sulfonic chloride, DCM, DMAP or $\mathrm{K}_{2} \mathrm{CO}_{3}$ (Microwave, 400 W); iv: (1) amino acid, $\mathrm{NaOH}$ (aq.), $0^{\circ} \mathrm{C}, \mathrm{TsCl}$. (2) THF dry, $\mathrm{BH}_{3}-\mathrm{SMe}_{2}$, reflux. (3) $\mathrm{DCM}, \mathrm{TsCl}, \mathrm{DMAP}, \mathrm{Py} ; \mathrm{v}: \mathrm{RSO}_{2} \mathrm{NH}_{2}, \mathrm{~K}_{2} \mathrm{CO}_{3}, \mathrm{BnEt}_{3} \mathrm{~N}^{+} \mathrm{Cl}^{-}, \mathrm{dioxane}, 90{ }^{\circ} \mathrm{C}$, $\mathrm{MsCl}, \mathrm{DCM}, 0^{\circ} \mathrm{C}$ to reflux; vi: (1) chloramine salts, $\mathrm{ACN}, \mathrm{PTAB}, 12 \mathrm{~h}$; (2) $\mathrm{IPrCu}(\mathrm{DBM}), \mathrm{Phl}=\mathrm{O}, \mathrm{RSO}_{2}-\mathrm{NH}_{2}$, chlorobenzene, r.t., 25 h; (3) $\mathrm{Rh} 2$ (cap) ${ }_{4}$, $\mathrm{TsNH}_{2}, \mathrm{NBS}, \mathrm{K}_{2} \mathrm{CO}_{3}$. 


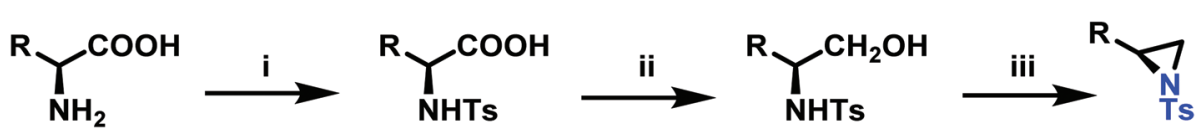

\section{$\mathrm{R}=\mathrm{HOCH} 2, \mathrm{Me}, \mathrm{iPr}, \mathrm{iBu}, \mathrm{PhCH} 2, \mathrm{MeS}(\mathrm{CH} 2) 2$}

Scheme 12 i: Preparation of $\mathrm{N}$-tosyl-2-aminoacids via $\mathrm{N}$-tosylation with $\mathrm{TsCl}$; ii: preparation of $\mathrm{N}$-tosyl-2-aminoalcohols reduction of the carbonyl group; iii: preparation of 2 -substituted $N$-tosylaziridines.

however, the yields vary depending on the pendant groups. Increasing the viability of this method, the catalysts are either commercially available or can be prepared with ease. ${ }^{128-130}$ Sharpless and coworkers proposed a mechanism for brominecatalyzed aziridination (Scheme 13). In the first step, the olefin reacts with a $\mathrm{Br}^{+}$source, given by PTAB. The brominium ion is then ring-opened by $\mathrm{TsNCl}^{-}$, to form the $\alpha$-bromo- $\mathrm{N}$-chloro- $\mathrm{N}$ toluenesulfonamide (Step 2). Attack of the bromide anion $\left(\mathrm{Br}^{-}\right)$ (or $\mathrm{TsNCl}^{-}$) on the $\mathrm{N}-\mathrm{Cl}$ group of the intermediate generates the anion and a $\mathrm{Br}-\mathrm{X}$ species (Step 3). Expulsion of $\mathrm{Br}^{-}$from the anion finally yields the aziridine and the regenerated $\mathrm{Br}-\mathrm{X}$ species (Step 4) initiates another turn of the catalytic cycle. ${ }^{130}$ This synthesis route has been successfully used for monomer

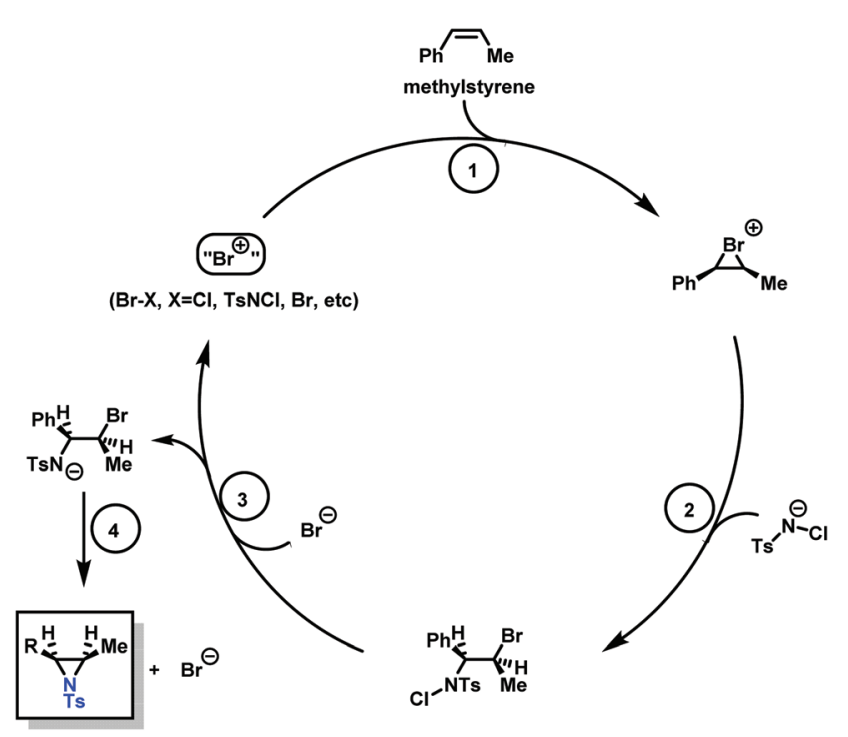

Scheme 13 Catalytic cycle of the PTAB catalyzed aziridination of olefins, adopted from previous work of Sharpless. Copyright@1998 The American Chemical Society. Reprinted with permission from Journal of the American Chemical Society. ${ }^{130}$ synthesis by the Wurm group by using chloramine-T and chloramine-M to synthesize MsDAz (49\%) and TsDAz (47\%) $)^{131}$ and acetal functionalized aziridine monomers (17\%-30\%). ${ }^{132}$

Epoxides were also used as attractive starting materials for the sulfonyl aziridine synthesis (Scheme 14). ${ }^{124,133}$ 2-Benzyl-1(2,4,6-triisopropylbenzene-sulfonyl)aziridine was synthesized in two-steps: the first step was the nucleophilic ringopening of 2-benzyloxirane with the primary sulfonamide $\left(2,4,6-{ }^{\mathrm{i}} \mathrm{Pr}_{3} \mathrm{C}_{6} \mathrm{H}_{2} \mathrm{SO}_{2} \mathrm{NH}_{2}\right)$. This reaction requires 0.1 eq. of potassium carbonate and $\mathrm{BnNEt}_{3}{ }^{+} \mathrm{Cl}^{-}$as catalyst in dioxane $(73 \%$ yield). The subsequent mesylation-cyclization of the hydroxylsulfonamide was achieved by the addition of mesyl chloride to activate the hydroxy group under basic conditions ( $86 \%$ yield). This route might be extended to other $N$-sulfonyl groups. ${ }^{134}$

Another route, starting from epoxides, was used by Bergman and Toste $^{124}$ to synthesize 2- $n$-decyl- $N$-methanesulfonyl aziridine (MsDAz). Thomi and Wurm ${ }^{133}$ followed this procedure to synthesize 2-(oct-7-en-1-yl)- $N$-mesylaziridine. This procedure involves three steps; first the epoxide is ring-opened with sodium azide to give the azido-hydroxyalkane as intermediate, which is converted in the second step, by a Staudinger reaction, to the corresponding alkyl aziridine. To activate the obtained aziridine for anionic polymerization mesylchloride is used to replace the $\mathrm{N}$-terminal hydrogen in the third step. Table 1 summarizes activated aziridines and azetidines which were successfully polymerized via azaanionic polymerization to date.

\subsection{Initiators for the anionic polymerization of activated aziridines}

The anionic ROP of sulfonyl aziridines is typically initiated by secondary $N$-sulfonamide-initiators, such as the alkali salts of $N$-benzyl-4-methylbenzenesulfonamide, ${ }^{138}$ $N$-pyrene-methanesulfonamide ${ }^{124,132,136}$ or butyl lithium (Table 2) ${ }^{143,144}$ Also a bifunctional initiator $N, N^{\prime}$-(1,4-phenylenebis(methylene))dimethane-sulfonamide was introduced in 2017. ${ }^{143}$ To date, the standard protocol uses alkali bis(trimethyl-

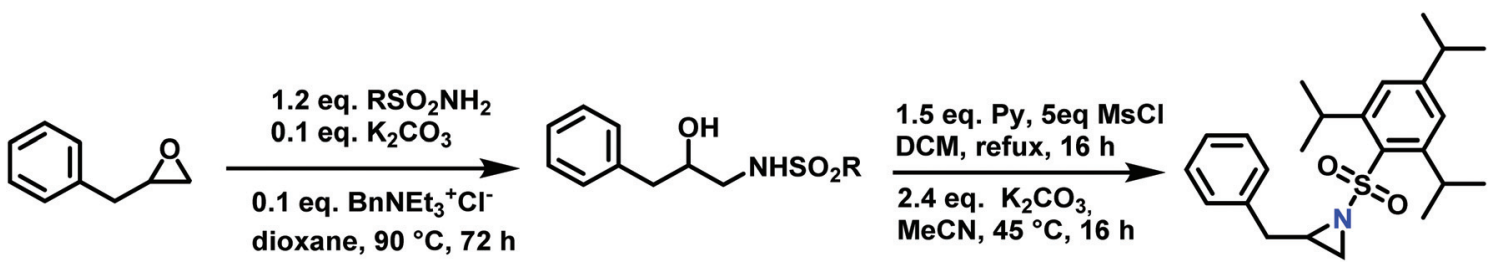

Scheme 14 Synthesis of 2-benzyl-1-(2,4,6-triisopropylbenzenesulfonyl)aziridine from 2-benzyloxirane, $R=2,4,6-{ }^{i} \operatorname{Pr}_{3} \mathrm{C}_{6} \mathrm{H}_{2}$. 
Table 1 Activated aziridines which were successfully tested for A-AROP

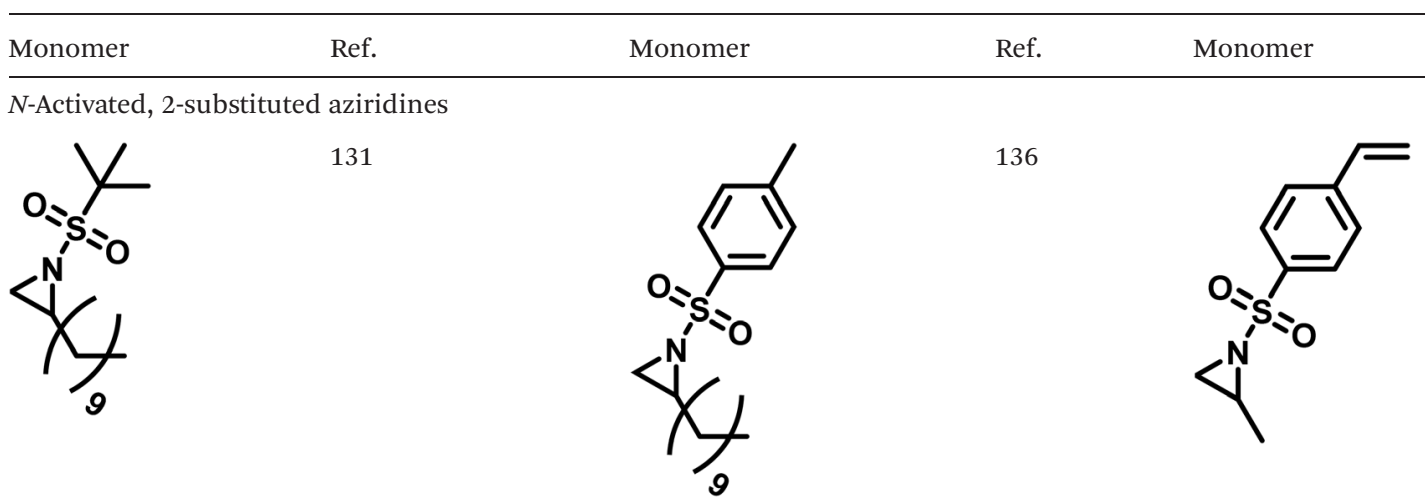

Ref.

131<smiles>Cc1ccc(S(=O)(=O)N2CC2CCO)cc1</smiles>

138<smiles>Cc1ccc(S(=O)(=O)N2C[C@H]2Cc2ccccc2)cc1</smiles>

131<smiles>CCOC(C)OC(C)(C)C1(C)CN1S(=O)(=O)c1ccc(C)cc1</smiles><smiles>CC1CN1S(=O)(=O)c1ccc(Br)cc1</smiles>

131

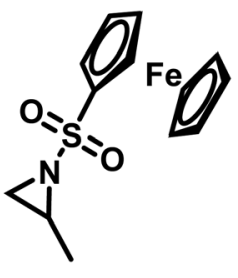

132

137

139

124

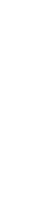

140<smiles>CC1CN1S(=O)(=O)c1ccc([N+](=O)[O-])cc1</smiles><smiles>C=C(C)CC1(C)CN1S(C)(=O)=O</smiles>

133 
Table 1 (Contd.)

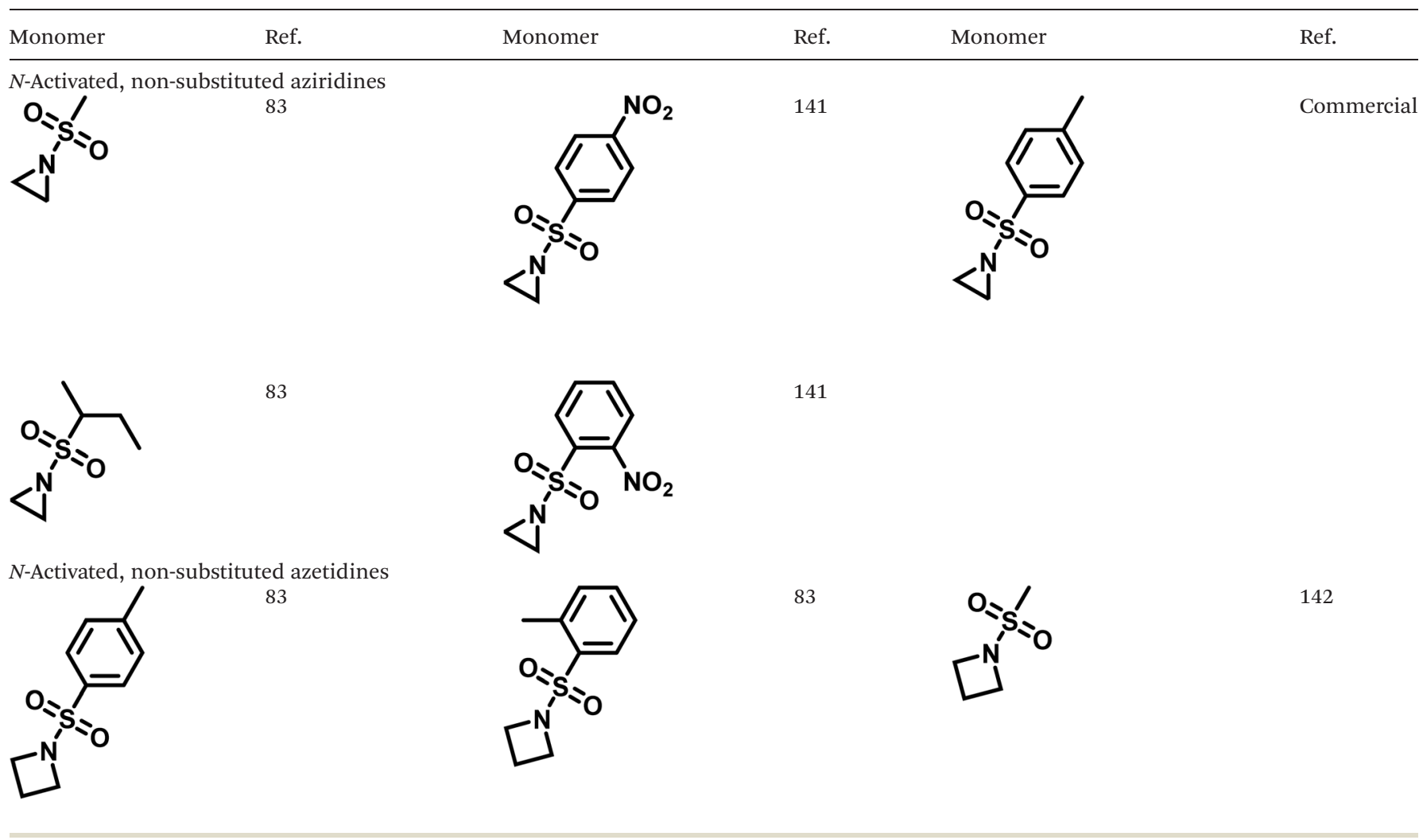

silyl)amide salts to deprotonate the sulfonamide-initiators. ${ }^{143}$ KHMDS alone was also proven to be able to ring-open sulfonyl aziridines, but bimodal molecular weight distributions were obtained. ${ }^{132,140}$ With these initiators, functional poly(sulfonylaziridine)s are available. Recently, Reisman et al. ${ }^{83}$ showed that the terminal group can be used to prepare telechelic polymers by terminating AROPs with propargyl bromide, which allows further modifications by click chemistry.

\subsection{Anionic polymerization of activated aziridines}

When initiated with a suitable nucleophile (Table 1), the anionic polymerization of sulfonyl aziridines follows living conditions (Scheme 15). ${ }^{143}$

The solubility of poly(sulfonylazirdine)s is highly dependent on the substituents on the sulfonyl group and the tacticity of the polymer. If (+)-2-benzyl- $N$-tosylaziridine was used as monomer, only insoluble oligomers were produced. ${ }^{124}$ In contrast, racemic monomers produce linear polymers with degrees of polymerization $\left(D_{\mathrm{P}}\right)$ of up to 200 (with $M_{\mathrm{n}}=20000$ $\mathrm{g} \mathrm{mol}^{-1}$ ) and narrow molecular weight distributions, $D<$ 1.10. ${ }^{124,143}$ Furthermore, the polymerization follows first order kinetics with respect to monomer, suggesting a living polymerization (Fig. 4). In addition, chain extension experiments proved that the polymerization of $\mathrm{N}$-sulfonylaziridines is living. The sulfonyl groups of the obtained poly(sulfonylaziridine)s can be removed after the polymerization with different strategies, e.g. using alkali metal naphthalides or acidic conditions to yield the corresponding polyamines (Scheme 15). ${ }^{82}$
The low solubility of poly(sulfonylaziridine)s was also a challenge for the polymerization of unsubstituted sulfonyl aziridines. In general, poly(sulfonylaziridine)s that lack substitution along the polymer backbone, or that have backbone substituents but are tactic, are generally insoluble in all solvents. For example, Thomi et al. ${ }^{144}$ attempted to polymerize tosylaziridine and found that only insoluble oligomers were obtained. Later, Rupar and coworkers ${ }^{83}$ were able to produce soluble polymers by copolymerizing mesylaziridine and sec-busylaziridine up to $D_{\mathrm{P}}=200$. Such copolymers produced well-defined linear polyamines after desulfonylation by lithium metal (Scheme 16).

Recently, Rupar and coworkers ${ }^{141}$ reported the first example of a poly(sulfonylaziridine) homopolymer which lacked substitution on the backbone. They studied the AROP of nitrophenylsulfonyl-activated aziridine monomers, namely $N$ - ( $p$-nitrophenyl)sulfonyl)aziridine ( $p \mathrm{NsAz})$ and $N$-((o-nitrophenyl)sulfonyl) aziridine (oNsAz) (Scheme 17). pNsAz formed an insoluble white powder upon heating in all attempts at polymerization. With $o \mathrm{NsAz}$, on the other hand, the resulting poly(oNsAz) was soluble in both DMF and DMSO at all molecular weights, making it the first example of a soluble poly( $N$-sulfonylaziridine) homopolymer. The obtained homopolymer was subsequently deprotected using sodium thiomethoxide in DMF at $50{ }^{\circ} \mathrm{C}$ to yield an off-white residue. Although evidence was found for the formation of LPEI from the deprotection of poly $(o \mathrm{NsAz})$, satisfactory purification of the residue was not achievable. Control over the molecular weight of poly $(o \mathrm{NsAz})$ was also attempted by initiating the anionic polymerization of $o \mathrm{NsAz}$ with $\mathrm{BnN}(\mathrm{Li}) \mathrm{Ms}$. However, the resulting poly $(o \mathrm{NsAz})$ was 
Table 2 Different initiators for the ring-opening polymerization of sulfonyl aziridines reported to date

Initiator $\quad$ Ref. $\quad$ Initiator<smiles>CS(C)(=O)=O</smiles>

IN

HN<smiles>CCc1ccc2ccc3cccc4ccc1c2c34</smiles><smiles>CS(=O)(=O)NCc1ccc(CNS(C)(=O)=O)cc1</smiles>

143

$\mathrm{N}_{3} \mathrm{SiMe}_{3}$

138<smiles>C=CCNS(=O)(=O)c1ccc(C)cc1</smiles>

124<smiles>CCC[Hg]</smiles>

143<smiles>OCCOCc1ccccc1</smiles>

Table 2 (Contd.)

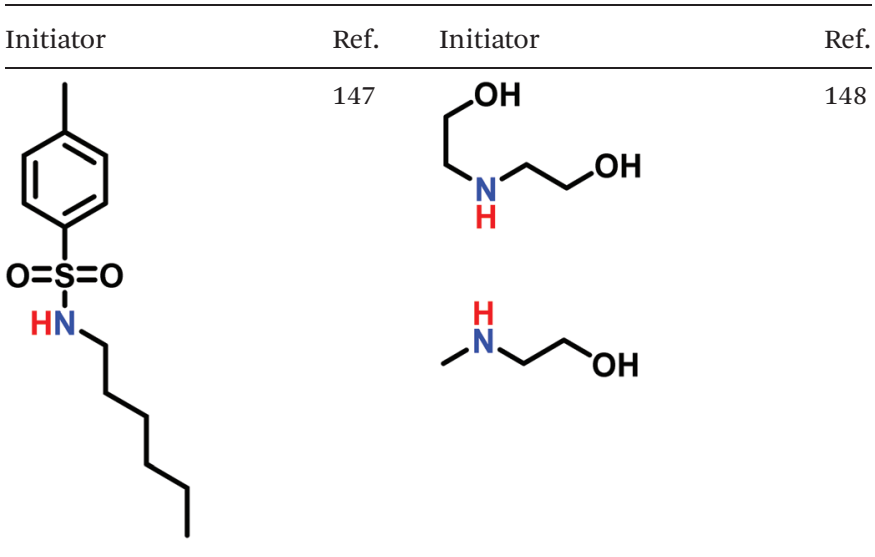

a mixture of the $\mathrm{BnN}(\mathrm{Li}) \mathrm{Ms}$ initiated polymer chains and hydroxyl initiated chains. This was attributed to the fact that $o \mathrm{NsAz}$ readily undergoes spontaneous polymerization, and thus could not be satisfactorily purified and dried.

Copolymerizations of different sulfonyl aziridines give access to random or gradient copolymers, depending on the nature of the sulfonyl group. ${ }^{136}$ The reactivity ratios of 2-methyl tosyl aziridine (TsMAz) and 2-decyl tosyl aziridine (TsDAz) were determined via real-time ${ }^{1} \mathrm{H}$ NMR spectroscopy and proven to be an ideal random copolymerization with $r($ TsMAz $)=1.08$ and $r($ TsDAz $)=0.98$ and $r($ TsMAz $) \cdot r($ TsDAz $)=$ 1.05. In contrast, combining monomers with different sulfonyl groups, resulted in (multi)gradient copolymers. ${ }^{131}$ Sulfonyl groups with stronger electron withdrawing effects increase the rate of polymerization, which led to gradient incorporation. Fig. 5 shows the real-time ${ }^{1} \mathrm{H}$ NMR kinetics of a statistical terpolymerization of 2-methyl brosylaziridine (BsMAz), 2-methyl tosyl aziridine (TsMAz), and 2-methyl mesylaziridine (MsMAz), which form a copolymer with distinct domins along the polymer chain, due to the individual reactivity ratios of each monomer. ${ }^{131}$ DFT-calculations of the electrophilicity indices $\left(\omega^{+}\right)$support these empirically determined comonomer reactivities, with BsMAz (2.22 eV) > TsMAz (1.98 eV) > MsMAz $(1.25 \mathrm{eV}) .{ }^{139}$ Contrarily, the nucleophilicity $\left(\omega^{-}\right)$of the azaanion at the growing chain end changes only ca. $0.14 \mathrm{eV}$, proving that the crucial factor which determines the incorporation rate is the monomer reactivity, and not the azaanion nucleophilicity. ${ }^{139}$

Gradient copolymers were also prepared by copolymerization of tosylated aziridines in emulsion. ${ }^{54}$ The comonomer pair TsDAz and TsMAz produce random copolymers in solution, but when separated from each other by an emulsion consisting of DMSO-droplets and cyclohexane as the continuous phase, variable gradients can be obtained by partitioning of both monomers, when the continuous phase is diluted. ${ }^{136,143,149}$ This is represented in the apparent reactivity ratios, which are $r_{\text {app }}($ TsMAz $)=4.98$ and $r_{\text {app }}($ TsDAz $)=0.20 \mathrm{in}$ case of a $1: 20$-DMSO/cyclohexane emulsion, revealing the formation of strong gradient copolymers. ${ }^{150-152}$ 

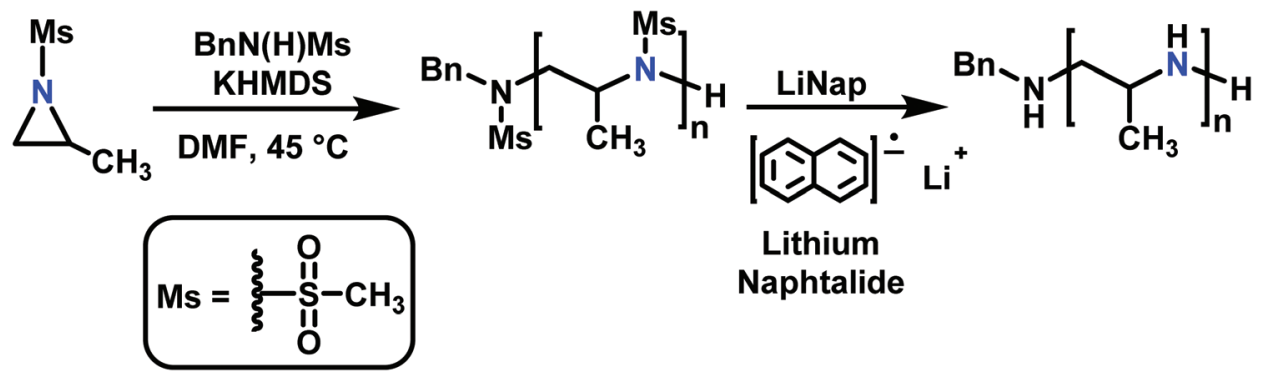

Scheme 15 Anionic ring-opening polymerization of sulfonyl aziridines and subsequent desulfonylation (with 2-methyl-mesylaziridine as an example).

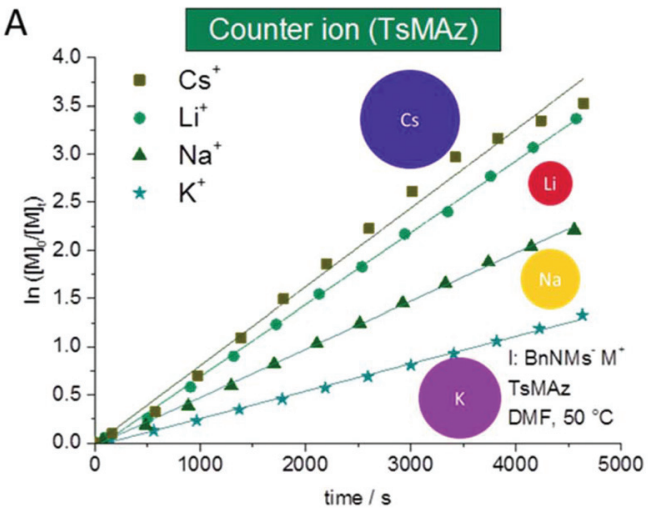

B

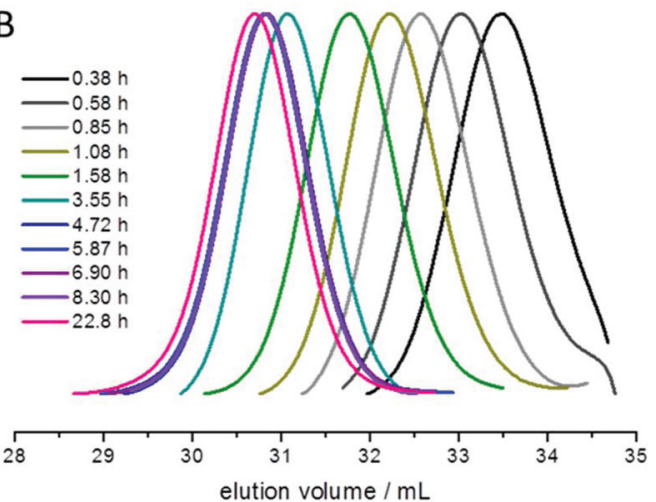

Fig. 4 (A) Kinetic plots of $\ln \left([\mathrm{M}]_{0} /[\mathrm{M}]_{t}\right)$ vs. time for the azaanionic polymerization of TsMAz with BnNHMs (initiator) in DMF- $d_{7}$ at $50{ }^{\circ} \mathrm{C}$ with different bis(trimethlsilyl)amide-salts. (B) SEC-kinetics of MsMAz, BnNKMs at $50^{\circ} \mathrm{C}$ in DMF (RI-signal), reproduced from ref. 143 with permission from Royal Chemical Society, copyright 2017.

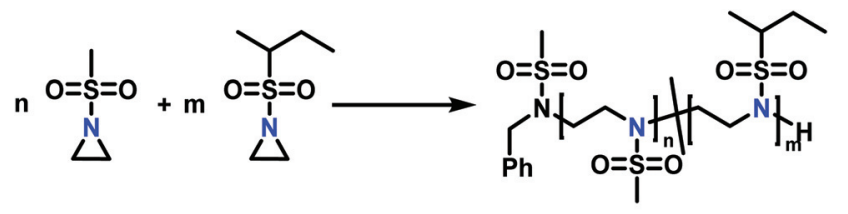

$\mathrm{n}=\mathrm{m} \rightarrow D_{\mathrm{p}} \approx \mathbf{2 0 0}$

$\mathrm{n}=\mathbf{0}$ or $\mathrm{m}=\mathbf{0}$ or $\mathrm{n} \neq \mathrm{m} \Rightarrow D_{\mathrm{p}} \leq 15$

Scheme 16 Azaanionic copolymerization of unsubstituted sulfonyl aziridines as precursors for LPEI. High degree of polymerization was only obtained when the monomers were used in a $1: 1$ ratio $(n=m)$. Other ratios produced only insoluble oligomers. ${ }^{83}$

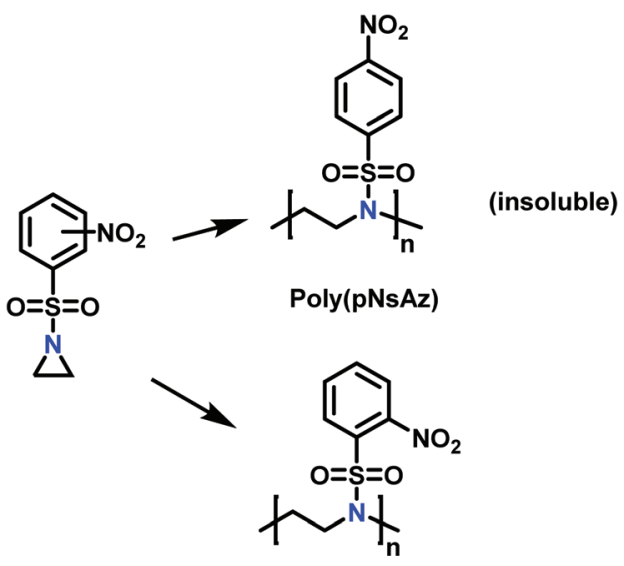

Poly(oNsAz)

Scheme 17 Azaaonionc polymerization of nitrophenylsulfonyl-activated aziridines. ${ }^{141}$

\subsection{Functional polyaziridines prepared by anionic polymerization}

Functional groups can be installed as substituents at the activating group or at the aziridine ring. 2-Oct(en)yl $N$-mesyl-aziridine (Fig. 6a) with an olefin functionality was homo- and copolymerized via AROP. The olefins were post-modified by a radical thiol-ene reaction with $N$-acetyl-L-cysteine methyl ester providing quantitative conversion. ${ }^{133}$ 2-Methyl- $N$-(4-styrenesulfonyl) aziridine (StMAz) ${ }^{137}$ was the first bivalent aziridine derivative to undergo either anionic or radical polymerization (Fig. 6d). After anionic polymerization, thiol-ene addition of mercaptoethanol or mercaptopropionic acid to the styrenic double bond was achieved. After radical polymerization, the pending sulfonyl aziridines could be further modified by nucleophilic additions, which was described for other polymers with aziridine side groups. ${ }^{153-156}$

Also, polyols have been prepared by the AROP of sulfonyl aziridines. In analogy to ethoxy ethyl glycidyl ether (EEGE), the well-known precursor in oxyanionic polymerization to obtain linear poly(glycerol) $)^{74,157}$ acetal-protected $N$-tosyl-activated aziridines were introduced in 2016 (Fig. 6b) ${ }^{132}$ Three different acetal-protected monomers with variable alkyl chain lengths were prepared and could be polymerized by living AROP. The 


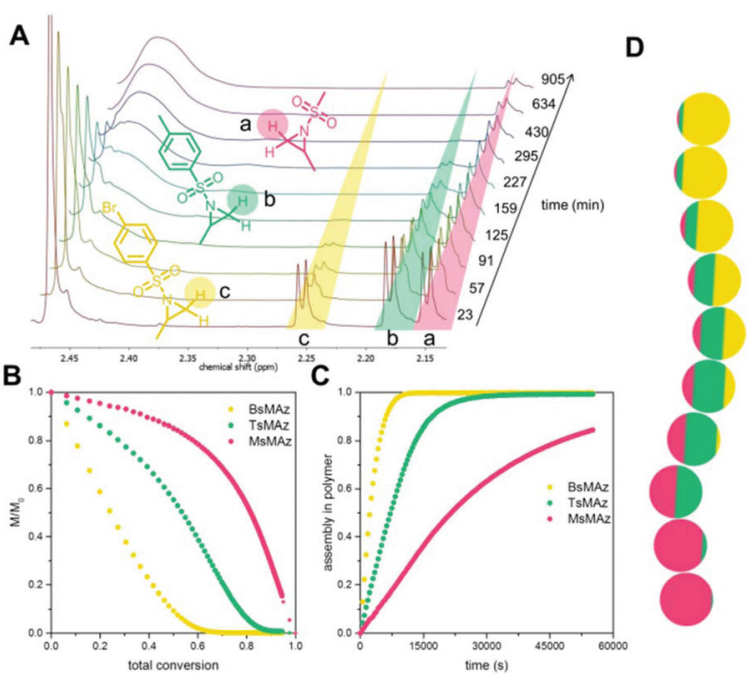

Fig. 5 Simultaneous copolymerization of BsMAz, TsMAz, and MsMAz. (A) Real-time ${ }^{1} \mathrm{H}$ NMR spectra of the terpolymerization of $\mathrm{BsMAz}$ (yellow), TsMAz (green), MsMAz (red) showing the consumption of the monomers. (B) Normalized monomer concentrations in the reaction vs. total conversion. (C) Assembly of each monomer in the polymer vs. reaction time. (D) Visualization of a single chain for poly(BsMAz-coTsMAz-co-MsMAz) - each sphere stands for $10 \%$ conversion. (Reproduced from ref. 131 with permission from Wiley, copyright 2016). hydroxyl groups were released by mild acidic hydrolysis, leaving the sulfonamides attached. Additional removal of the sulfonyl groups under reductive conditions resulted in polyamine-polyols, which might be used as chelating or transfection agents. ${ }^{132}$

Organometallic 2-methyl- $N$-ferrocenylsulfonyl-aziridine was polymerized to prepare redox-responsive poly(sulfonylaziridine)s (Fig. 6c). ${ }^{140}$ Similar to other poly(sulfonylaziridine)s (see above), the homopolymerization resulted in insoluble materials. However, solid state NMR (ssNMR) and MALDI-TOF spectra supported the expected polymeric structure. Copolymerization with TsMAz or MsMAz resulted in soluble copolymers with moderate molecular weight dispersities $(D<1.4)$, and chain extension experiments proved the living nature of the polymerization. Such organometallic polymers showed reversible oxidation/reduction by cyclic voltammetry, similar to other ferrocene-containing polymers. ${ }^{158}$

\section{Anionic polymerization of azetidines}

Reisman et al. ${ }^{142}$ reported the first example of AROP of an azetidine monomer, $N$-(methanesulfonyl)azetidine (MsAzet)

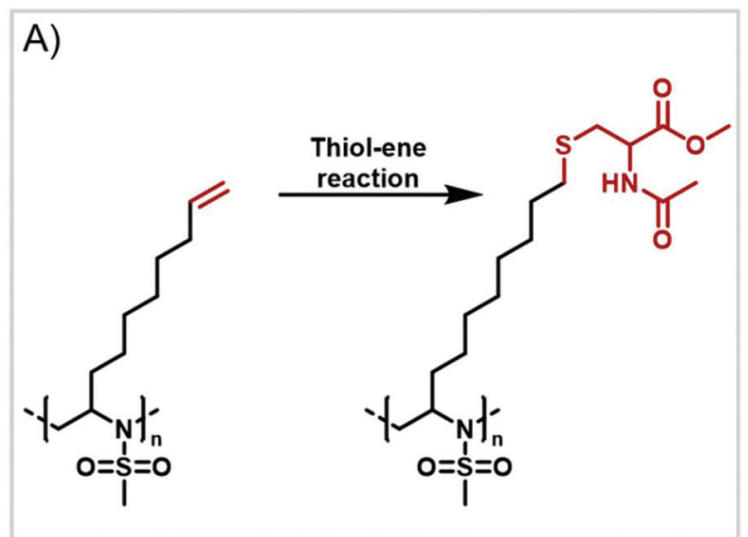

B)
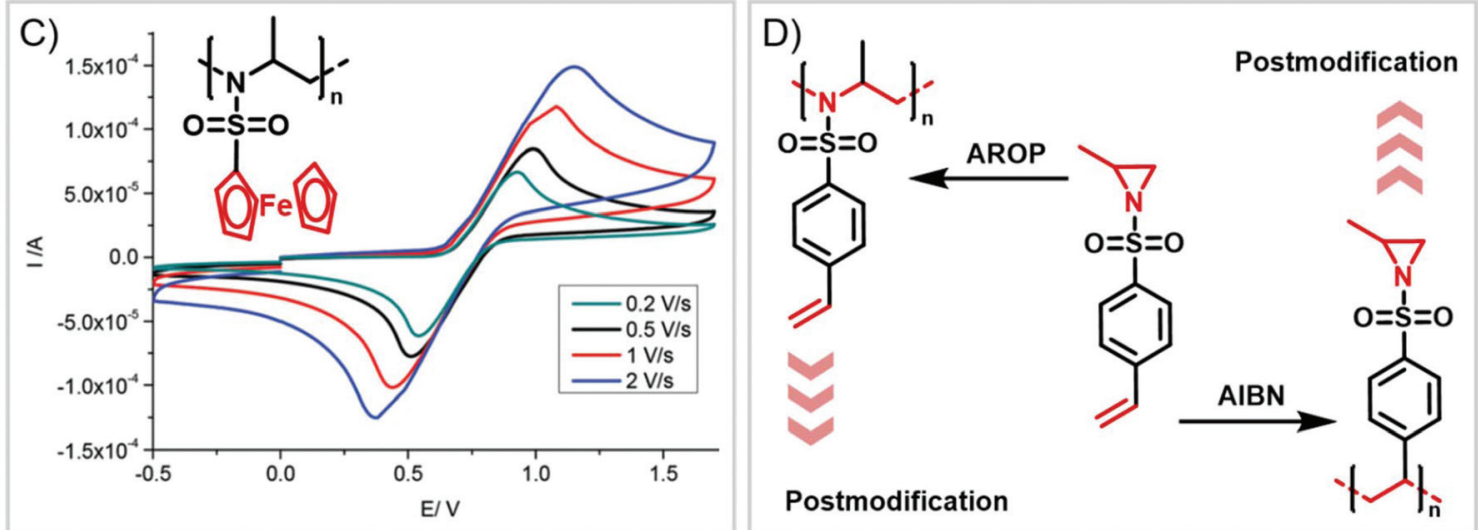

Fig. 6 Functional polyaziridines: (A) terminal double bond can be converted via thiol-ene reaction. (B). Acetal-protected polyaziridines yield hydroxyl functionalities. (C) Ferrocene-containing polyaziridines are redox-responsive. (D) Orthogonal aziridine allows anionic and radical polymerization. 


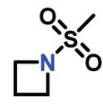

1. ${ }^{\mathrm{B} u N(K) M s}$

$\mathrm{DMSO}_{\mathrm{d} 6}$

$160^{\circ} \mathrm{C}$

2. $\mathrm{H}_{2} \mathrm{O}$

MsAzet
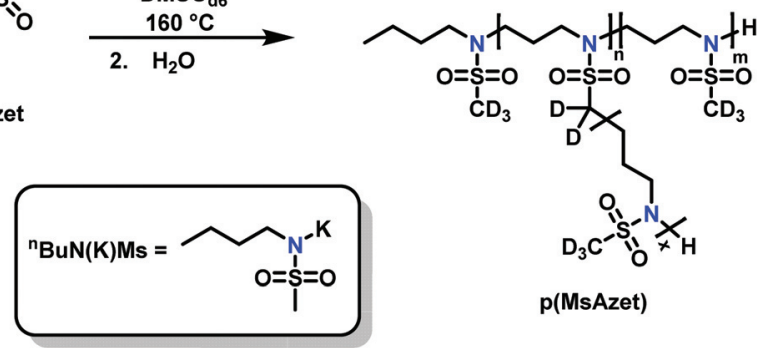

p(MsAzet)

Scheme 18 Anionic ring-opening polymerization of $\mathrm{N}$-(methanesulfonyl)azetidine. ${ }^{142}$

(Scheme 18). Unlike the three-membered ring sulfonylaziridines, the polymerization of MsAzet required high temperatures $\left(>100{ }^{\circ} \mathrm{C}\right)$ in order to polymerize. The resulting polymer, $\mathrm{p}$ (MsAzet), proved to contain branching due to chain transfer. As evidenced by $\mathrm{H}-\mathrm{D}$ exchange experiments, this chain transfer occurs through the deprotonation of methanesulfonyl groups of the polymer backbone and the monomer to form sulfamoyl methanide anions. Evidence of minimal chain transfer to DMSO that occurs through the formation of dimsyl anions was also found. More importantly, the concentration of the active chain ends was found to be constant during the polymerization of MsAzet, which indicates that the controlled and living polymerization of sulfonylazetidines can be made possible if chain transfer can be inhibited.

Recently, $N$-(tolylsulfonyl)azetidines were found to undergo living AROP to form linear polymers. ${ }^{159}$ These monomers do not contain protons likely to be activated under the polymerization conditions. Initial work was done by attempting to produce homopolymers from the two monomers $N$ - $(p$-tolylsulfonyl)azetidine ( $p$ TsAzet) and $N$-(o-tolylsulfonyl)azetidine (oTsAzet) by AROP (Scheme 19). However, both resulting

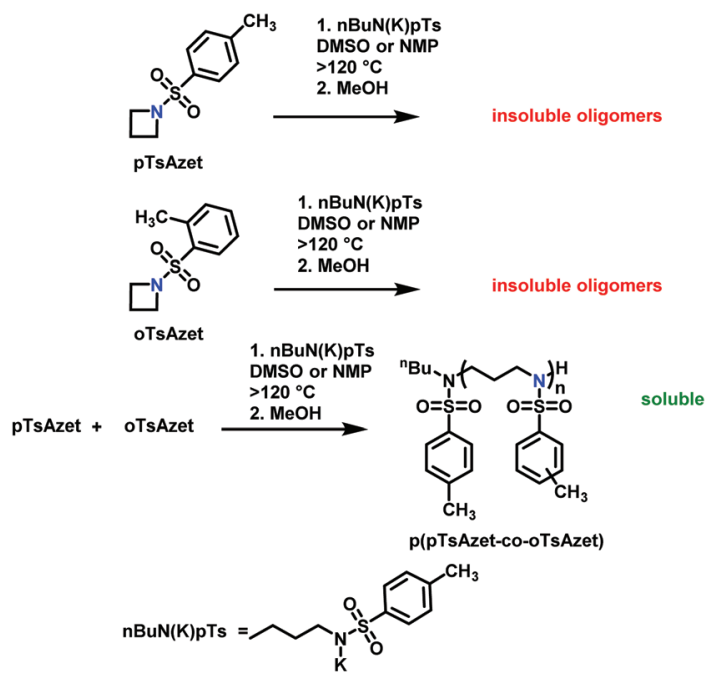

Scheme 19 Polymerization of TsAzet monomers to produce insoluble homooligomers and a soluble copolymer. ${ }^{159}$ homopolymers precipitated from solution during polymerization at low molecular weight, similarly to sulfonylaziridine homopolymers. ${ }^{83,144}$ Drawing motivation from the literature, in which the copolymerization of two sulfonylaziridines was used to produce a soluble copolymer, ${ }^{83}$ the copolymerization

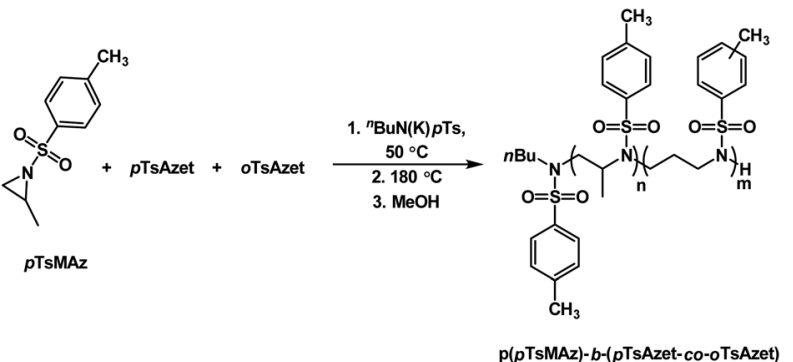

Scheme 20 Block copolymerization of pTsMAz with oTsAzet and $p$ TsAzet to produce $\mathrm{p}(\mathrm{pTsMAz})-b-\mathrm{p}(p \mathrm{TsAzet}-\mathrm{co}-\mathrm{oTs}$ Azet).

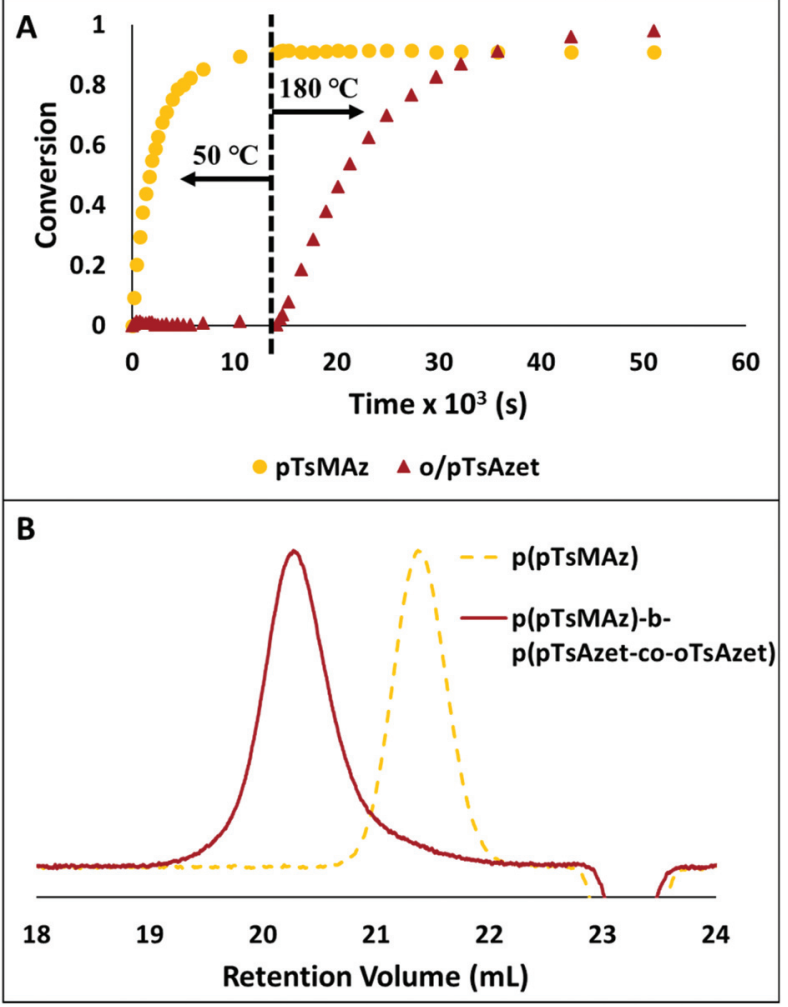

Fig. 7 (A) Plot of conversion vs. time for the block copolymerization of $p$ TsMAz, $p$ TsAzet, and oTsAzet in $\mathrm{DMSO}_{\mathrm{d}_{6}}$ to produce $\mathrm{p}(p \mathrm{TsMAz})_{20}-b-p$ ( $p$ TsAzet-co-oTsAzet) 40 . The reaction is kept at $50{ }^{\circ} \mathrm{C}$ for $4 \mathrm{~h}$, then heated to $180{ }^{\circ} \mathrm{C}$ for $10.25 \mathrm{~h}$. The ${ }^{1} \mathrm{H}$ NMR measured conversion of pTsMAz appears to not reach $100 \%$ due to signal overlap between the monomer and polymer resonances in ${ }^{1} \mathrm{H}$ NMR spectra of the reaction mixture. (B) SEC trace of $\mathrm{p}(p T s M A z)_{20}$ prior to block copolymer chain extension (---). SEC trace of $\mathrm{p}(p \mathrm{TsMAz})_{20}-b-\mathrm{p}\left(p\right.$ TsAzet-co-oTsAzet) ${ }_{80}$ (- Block copolymerization to produce $\mathrm{p}(p T s M A z)_{20}-b-p$ (pTsAzet-co-oTsAzet) $)_{80}$ was performed with a [pTsMAz] : [oTsAzet] : [pTsAzet] : [l] ratio of $20: 40: 40: 1$ in NMP at $70{ }^{\circ} \mathrm{C}$ for $12 \mathrm{~h}$, then $205^{\circ} \mathrm{C}$ for $16 \mathrm{~h}$. Reproduced from ref. 159 with permission from American Chemical Society, copyright 2018. 
of $p$ TsAzet with oTsAzet was attempted and produced the soluble copolymer, $\mathrm{p}$ (p TsAzet-co-oTsAzet) (Scheme 19). Similarly to MsAzet, the polymerization showed first order kinetics with respect to the total monomer concentration and the number of active chain ends remains constant. By a series of polymerizations, it was demonstrated that the polymerization was both living and controlled and produced polymers with narrow molecular weight distributions. The sulfonyl groups of $\mathrm{p}(p$ TsAzet-co-oTsAzet $)$ were removed under reductive conditions to produce the first example of LPTMI by living anionic polymerization.

Additionally, due to the need for high temperatures in order to polymerize, the $N$-(tolylsulfonyl)azetidines could be used to produce block copolymers by living anionic polymerization in a closed-system in which all monomers are present at the time of initiation (Scheme 20, Fig. 7). ${ }^{159}$ This was accomplished by combining all monomers, $p$ TsMAz, $p$ TsAzet, and oTsAzet, in solution prior to initiation. Due to the differences in reactivities, $p$ TsMAz could be polymerized selectively at lower temperatures $\left(50{ }^{\circ} \mathrm{C}\right)$ while $p$ TsAzet and $o$ TsAzet do not polymerize. Upon total consumption of $p$ TsMAz, the temperature was increased to $180{ }^{\circ} \mathrm{C}$ to polymerize $p$ TsAzet and $o$ TsAzet to produce block copolymers. This allowed for the formation of block copolymers without homopolymer impurities. In the field of high performance block copolymers, this finding is of particular importance, as small amounts of homopolymer impurities can alter the properties of block copolymer materials.

\section{Organocatalytic ring-opening polymerization (OROP) of activated aziridines}

$\mathrm{N}$-Heterocyclic carbenes (NHC), such as 1,3-bis(isopropyl)-4,5 (dimethyl)imidazole-2-ylidene, are powerful catalysts in many types of polymerizations. Their near unlimited structural diversity, inherent high Brønsted-basicity, and nucleophilicity make NHCs powerful organocatalysts. ${ }^{160,161}$ Examples of applications of NHCs include some of the most important commercial monomers in the step-growth polymerization of terephthalaldehyde, ${ }^{162}$ the group transfer polymerization of methacrylic monomers, ${ }^{163}$ and the zwitterionic ring-opening polymerization (ZROP) of ethylene oxide (EO), ${ }^{164}$ which was discovered in 2009 by Taton and coworkers. As activated aziridines polymerize with nucleophilic bases, similar to EO, via AROP, it was of interest if organocatalytic ring-opening polymerization (OROP) can also be successfully performed with this new monomer class. The first living OROP of 2-alkyl- $N$-sulfonyl aziridines was presented by Carlotti, Taton and coworkers in 2016 (Scheme 21). ${ }^{147}$ The OROP of $N$-tosyl-2-substituedaziridines takes place in the presence of 1,3-bis(isopropyl)-4,5 (dimethyl)imidazole-2-ylidene, as a sterically hindered organocatalyst, and activated secondary $N$-tosyl amine as the initiator. This mechanism offers a mild and metal-free route for the polymerization of activated aziridines to obtain identical poly-

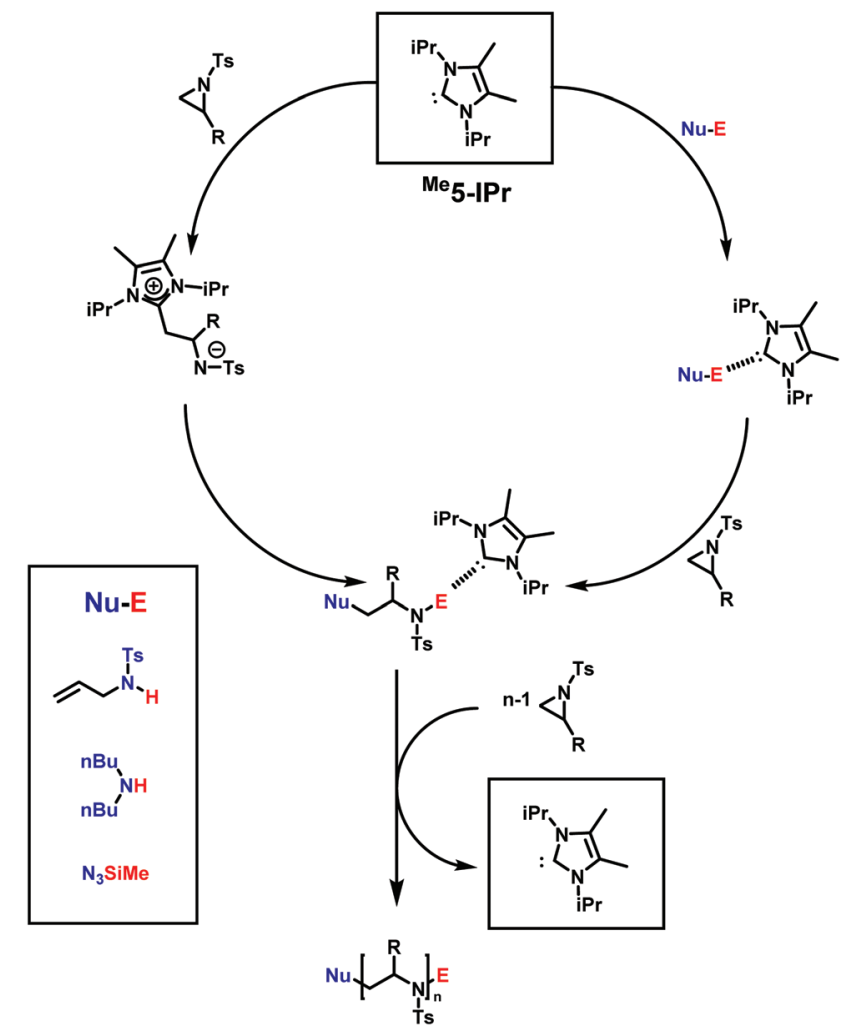

Scheme 21 Possible mechanism for the NHC-OROP of 2-alkyl N-ptoluenesulfonyl aziridines initiated by $N$-allyl $N$-p-toluenesulfonyl amine, di- $n$-butylamine and trimethylsilyl azide. Reproduced from ref. 145 with permission from Elsevier, copyright 2017.

aziridines to those from AROP, with narrow molecular weight distributions $(1.04<D<1.15)$ and molecular weights up to $21000 \mathrm{~g} \mathrm{~mol}^{-1}$. Depending on the steric hindrance of the ringsubstituent, on the monomer, the reaction time to full conversion varies between 1 and 5 days at $50^{\circ} \mathrm{C}$ in THF.

Depending on the nature of the monomers, the NHCs either react as nucleophilic initiators or behave as organic catalysts by activating the initiator/active chain end. MALDI-TOF spectrometry clearly demonstrated the incorporation of the initiator (secondary $\mathrm{N}$-tosyl amines) into the polymer, and a distribution with NHCs covalently bond to the polymer was not observed. The scope of practical initiators was expanded, when non-activated amines ${ }^{145}$ and unprotected aminoalcohols were investigated, which allows further post-modification of the poly(aziridine)s.

Carbene-organocatalyzed ring-opening polymerization (NHC-OROP) of activated aziridines has also been conducted with an unprotected aminoalcohol as the initiator. The NHC catalyst selectively initiated the polymerization at the secondary amine, while the alcohol group remained untouched. ${ }^{148}$ This allows for the synthesis of hydroxyl-functionalized poly(sulfonylaziridine)s which can be employed as macroinitiators for the synthesis of block copolymers. The hydroxyl group was used to initiate the ROP of lactide, catalyzed by the same carbene, to prepare PAz- $b$-PLLA diblock copolymers (Scheme 22). ${ }^{148}$ 

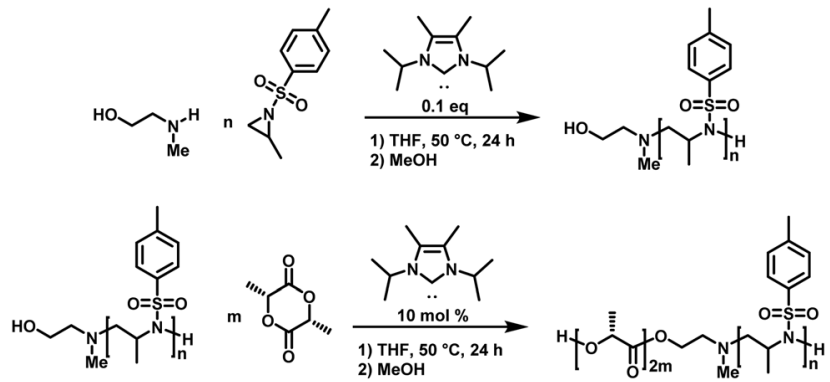

Scheme 22 NHC-OROP of TsMAz initiated by 2-(methyl amino) ethanol, synthesis of poly(TsMAz)-b-poly(L-lactide) by sequential NHC-OROP with ${ }^{\text {Me }} 5$-IPr as organocatalyst. ${ }^{148}$

Recently, another metal-free azaanionic polymerization of sulfonyl aziridines was reported, ${ }^{138}$ relying on different organic superbases, namely TMG, DBU, MTBD, TiPP and $t$-Bu$\mathrm{P}_{4}$ (Scheme 23). The basicity ( $\mathrm{p} K_{\mathrm{a}}$-values of the conjugated acids) of these compounds increases in the order TMG $<$ DBU $<$ MTBD $<$ TiPP $<t$-Bu- $\mathrm{P}_{4}$ and correlates with their increasing catalytic activity. The OROP performed best (regarding reaction time (20 min), conversion, and dispersity $(\nexists=1.05))$ using the most basic organic base, $t$-Bu- $\mathrm{P}_{4}$, but TiPP also showed satisfactory results. The remaining three bases were found to catalyze the polymerization of sulfonyl aziridines but showed higher molecular weight distributions ( $\theta$ up to 1.4). This is caused by the increased nucleophilicity of the bases leading to multiple initiators with varying rates of initiation. Overall, the strongest bases had the best catalytic activity. Moreover, the amount of catalyst could be lowered to $0.05 \%$ respect to the initiator, which indicates a very fast proton exchange, similar to oxyanionic polymerizations. ${ }^{74}$

\section{Desulfonylation reactions}

LPEI is a linear polyamine, which is of high interest for applications in non-viral gene transfection and as polyelectrolytes. ${ }^{167}$ Today LPEI is produced from polyoxazolines following hydrolysis of the pendant amides (see above). ${ }^{16,26,165,166}$ The primary attraction to synthesizing linear PEI via the oxazoline route is due to the controlled character of the cationic polymerization of poly(2-oxazoline)s, which allows control over molar masses and dispersity. ${ }^{168}$ Generally, strongly acidic or alkaline media, and temperatures as high as $100{ }^{\circ} \mathrm{C}$ are required to transform acylated poly(2-oxazoline)s into LPEI, a process that is difficult to drive to completion. In a recent publication, Tauhardt and coworkers reported 99\% hydrolysis of poly(2-oxazoline)s using $6 \mathrm{M} \mathrm{HCl}$ at $130{ }^{\circ} \mathrm{C}$ in a microwave synthesizer; the closest to complete conversion to LPEI from a poly(2-oxazoline) yet reported. ${ }^{169}$

In contrast, if aziridines or azetidines are polymerized by an anionic or organocatalytic route, desulfonylation of the poly (sulfonamide)s needs to be achieved. Many published strategies exist in the literature for the reduction of low molecular weight sulfonamides to amines. ${ }^{170,171}$ According to Bergman and Toste, ${ }^{124}$ a successful desulfonylation of poly(sulfonylaziridine) was achieved by lithium napthalenide. However, no spectral analyses or molecular weight distributions of the obtained structures were given. In another approach from Wurm's group, ${ }^{144}$ tosylamides were cleaved by acidic hydrolysis with hydrobromic acid ( $\mathrm{HBr}$ ) and phenol. In spite of the harsh reaction conditions, the method was reported to be successful. Later, Wurm and coworkers were able to remove tosylamides with sodium bis(2-methoxyethoxy)aluminiumhydride (Red-Al)
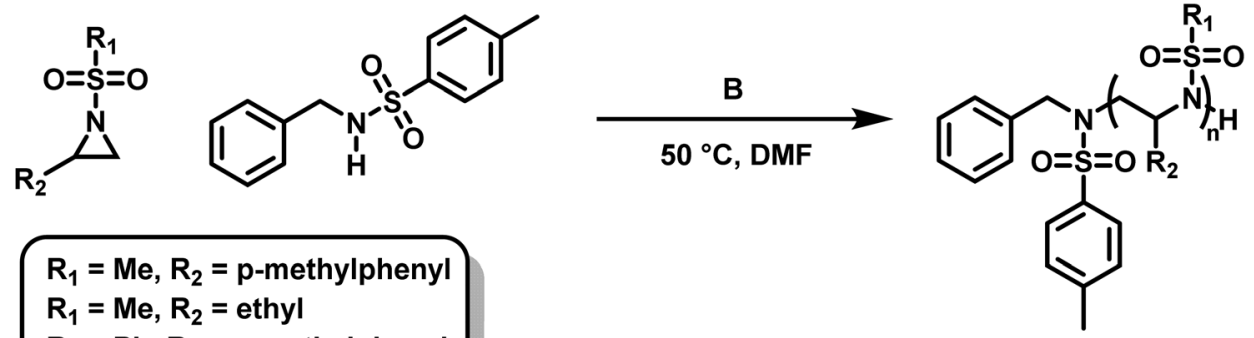

$\mathbf{R}_{1}=M e, \mathbf{R}_{2}=$ p-methylphenyl
$\mathbf{R}_{1}=M e, \mathbf{R}_{\mathbf{2}}=$ ethyl
$\mathbf{R}_{\mathbf{1}}=\mathbf{P h}, \mathbf{R}_{\mathbf{2}}=$ p-methylphenyl

$50^{\circ} \mathrm{C}, \mathrm{DMF}$
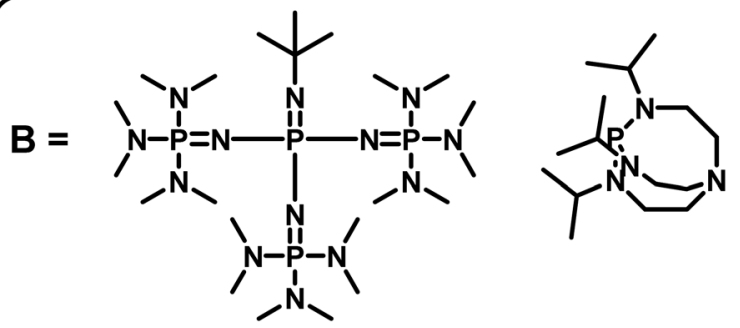<smiles>CN1CCCN2CCCN=C12</smiles><smiles>C1CCC2=NCCCN2CC1</smiles><smiles>CN(C)C(=N)N(C)C</smiles>

t-Bu-P4 (pKa 42.7)

TiPP (pKa 33.63) MTBD (pKa 25.43) DBU (pKa 24.33) TMG (pKa 23.3)

Scheme 23 AROP of $N$-sulfonyl aziridines mediated by organic superbases. ${ }^{138}$ 


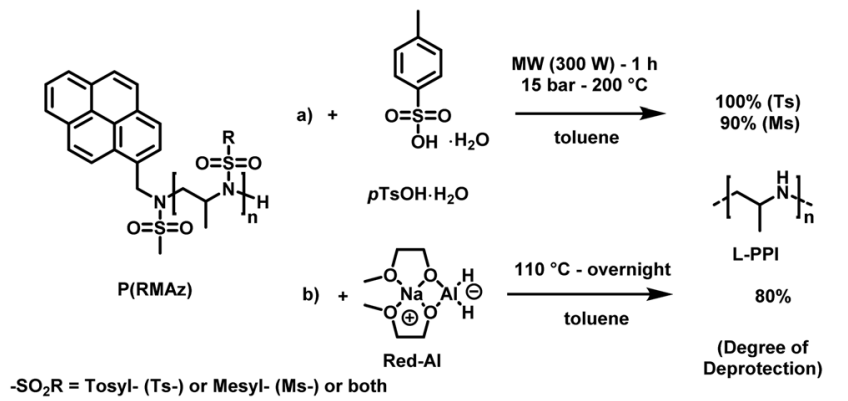

Scheme 24 Desulfonylation methods for PAz: (a) acidic hydrolysis, using $p \mathrm{TsOH}$ in toluene under microwave irradiation. (b) Reductive deprotection using Red-Al in toluene. ${ }^{82}$

to $\sim 80 \%$ (Scheme 24). ${ }^{132}$ Rupar and coworkers were able to prepare LPEI under reductive conditions, using elemental lithium (Li), with tert-butanol $(t$-BuOH) in hexamethylphosphoramide (HMPA) and THF at low temperatures. ${ }^{83}$ Acidic hydrolysis under microwave irradiation, which proved to be efficient for hydrolysis of polyoxazolines, ${ }^{171,172}$ also produced desulfonylated linear polypropylenimine (LPPI, 100\% desulfonylation for tosyl groups and ca. 90\% for mesyl groups). ${ }^{82}$ However, chain scission could not be prevented under these harsh conditions.

\section{Combination of aziridines and azetidines with other polymerization techniques: copolymers and polymer architectures}

\subsection{Copolymers of aziridines with $\mathrm{CO}_{2}$}

Ihata et al. synthesized poly(urethane-co-amine)s by copolymerization of several aziridines with $\mathrm{CO}_{2}$ (Scheme 25). ${ }^{173,174}$ The polymerizations were performed without the addition of catalyst or initiator in supercritical $\mathrm{CO}_{2}$ as the solvent, produ- cing branched polymers of molar masses between 7000 and $15000 \mathrm{~g} \mathrm{~mol}^{-1}$. Branching occurs during the polymerization, when the secondary amines react with $\mathrm{CO}_{2}$, resulting in a carbamate and a protonated aziridine. The latter is ring-opened by nucleophilic attack, leading to branched polymers. The ratio of urethane to amine linkages in the poly(urethane-coamine)s is affected by the $\mathrm{CO}_{2}$ pressure. By variation of the $\mathrm{CO}_{2}$ pressure from 3 to $22 \mathrm{MPa}$, copolymers with urea contents from 32 to $62 \%$ were produced. The reported yields were $<35 \%$ and decreased further when the aziridine was substituted with sterically demanding side groups (i.e. 2,2 dimethylaziridine, 2-cyclohexylaziridine, etc.). The copolymers of methylaziridine and $\mathrm{CO}_{2}$ exhibited lower critical solution temperatures in water between 34 to $85{ }^{\circ} \mathrm{C}$, which might be beneficial for the development of smart nanomaterials.

\subsection{Copolymers of aziridines with $\mathrm{CO}$}

Jia et al. explored the alternating copolymerization of aziridine with carbon monoxide mediated by a cobalt catalyst to prepare polyamides (Scheme 26). ${ }^{175}$ High CO pressures of up to $69 \mathrm{bar}$ were necessary to obtain high polymer yields of $c a$. $90 \%$. High molecular weight polyamides between 14100 and 63300 $\mathrm{g} \mathrm{mol}^{-1}$ were synthesized. However, molar mass dispersities of up to 11.5 indicate low degrees of control over the polymerization. The authors further proposed a mechanism, in which consecutive aziridine attacks during the polymerization could lead to an amide-amine copolymer, to rationalize the broad distributions of the polymers. The amine linkages act also as nucleophiles and thereby induce branching or crosslinking. ${ }^{176}$

Well-defined poly- $\beta$-peptoids can be obtained in quantitative yields with $D=1.11$ when $N$-alkylated aziridines are copolymerized with carbon monoxide (Scheme 27). ${ }^{177} \mathrm{~N}$-Methyl and $\mathrm{N}$-ethyl groups enhance the selectivity of the cobalt catalyst and improve the alternating copolymerization. The mechanism involves aziridine insertion into the cobalt-acyl bond, with the rate determining step being the ring-opening of the aziridine, followed by a migratory $\mathrm{CO}$ insertion. ${ }^{178}$ As crossover
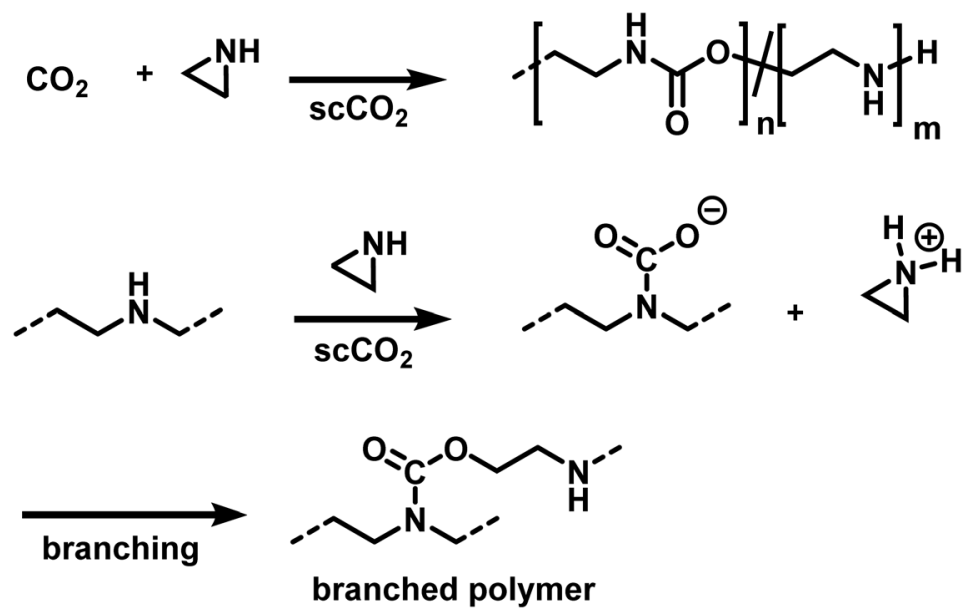

Scheme 25 Copolymerization of aziridines and $\mathrm{CO}_{2}$ to branched poly(urethane-co-amines)s. ${ }^{173,174}$ 

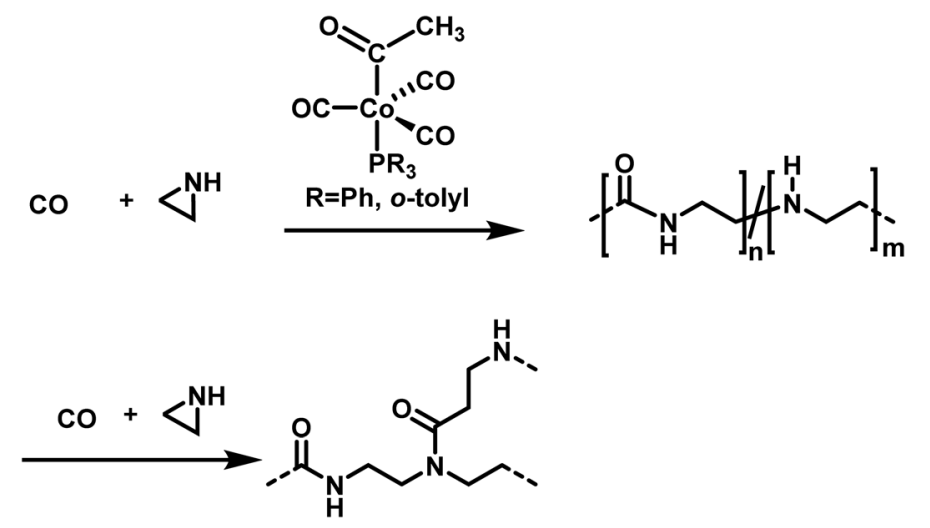

Scheme 26 Copolymerization of aziridine and carbon monoxide towards branched poly(amide-co-amines)s. ${ }^{175}$

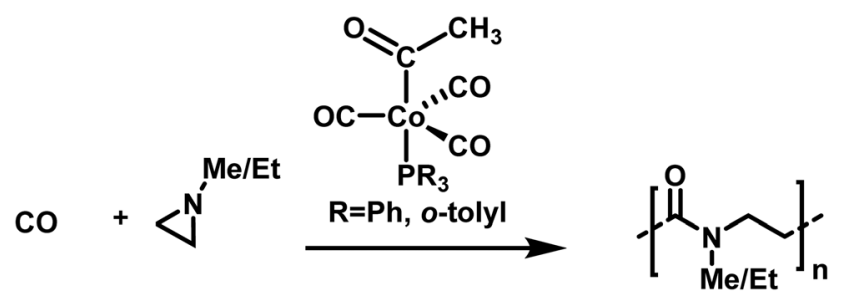

Scheme 27 Alternating copolymerization of alkylated aziridines and carbon monoxide towards well-defined poly- $\beta$-peptoides. ${ }^{177}$

reactions, chain transfer, or combination reactions were not observed, the copolymerization of $N$-substituted aziridines with $\mathrm{CO}$ seems to follow the characteristics of a living alternating copolymerization.

\subsection{Copolymers of azetidines with CO}

More recently, Jia provided the first example of a transition metal catalyzed azetidine polymerization. ${ }^{179}$ This work provided a route to $\operatorname{poly}(\gamma$-lactams $)$ by overcoming the difficulties associated with the ring-opening polymerization of $\gamma$-lactams. ${ }^{180}$ This was accomplished by using a cobalt catalyst to perform a carbonylative polymerization with $N$ - $n$-butylazetidine and $N$-iso-butylazetidine. While the polymer contains only amide units for $N$-iso-butylazetidine, in the case of $N-n$ butylazetidine, it was discovered that $\mathrm{CO}$ is unincorporated in some instances, leaving tertiary amines along the back bone of the polymer. ${ }^{181}$ Interestingly, it was discovered that THF also participates in the reaction, leading to the formation of ester units in the polymers produced (Scheme 28).

This was a significant finding as the incorporation of THF does not occur in the related aziridine systems. ${ }^{175-177,182,183}$ Further probing of the incorporation of THF led to the finding that increased azetidine concentration produced polymers with lower degrees of ester incorporation. This suggests that the reaction of the active chain end with THF is favored when the azetidine concentration is low. The living character, displayed by narrow molecular weight distributions and the linear increase in molecular weight with increase in conver- sion, coupled with in situ IR spectroscopy, suggests that the incorporation of ester units into the polymer backbone likely occurs in a gradient manner. The cobalt catalyzed carbonylative polymerization of azetidine does have a drawback in that the formation of $\gamma$-lactam also occurs. This reaction was attributed to "back-biting", ${ }^{178}$ rather than catalyst decomposition ${ }^{183}$ due to the continued living character of the polymerizations. Jia further hypothesized that this back-biting reaction occurs at the acylazetidinium intermediate, and not the acyl-Co(CO) $)_{4}$ intermediate. ${ }^{180}$ This hypothesis was tested by the addition of nucleophilic $\mathrm{I}^{-}$anions to facilitate ring-opening of the acylazetidinium intermediate. The addition of LiI ( 2 eq. relative to Co catalyst) eliminated the $\gamma$-lactam side-product, confirming Jia's hypothesis. Curiously, it was also found that the Li counter ion also played a role in the polymerizations. This was discovered because while $n \mathrm{Bu}_{4} \mathrm{NI}$ also suppressed the formation of $\gamma$-lactam, it greatly slowed the rate of polymerization. Interestingly, the addition of LiI also prevented the formation of ester linkages prior to complete consumption of azetidine. This finding allowed for the formation of block copolymers (Scheme 29). To further support the hypothesis of the $\mathrm{Li}^{+}$ cation being instrumental in the polymerization, no ester linkages were formed when $n \mathrm{Bu}_{4} \mathrm{NI}$ was used as an iodide source.

Due to the cobalt catalyzed carbonylative polymerization of azetidine having a living character, equal feeds of monomer were added over time in order to produce alternating amide and ester blocks. These polymers yielded narrow molecular weight distributions $(<1.23)$ and produced low molecular weight polymers with similar dispersities (1.11-1.30) upon methanolysis under acidic conditions at room temperature. Complete degradation of the resulting polyamides could be further achieved by refluxing the polymers in aqueous acidic conditions. This allows for poly(amide-co-ester) block copolymers to undergo a two-stage degradation.

\subsection{Combination of aziridines with other anionic polymerization techniques}

In living anionic polymerization (LAP) no termination occurs, allowing the synthesis of block copolymers by sequential addition of the monomers. Thomi et al. ${ }^{144}$ prepared poly- 


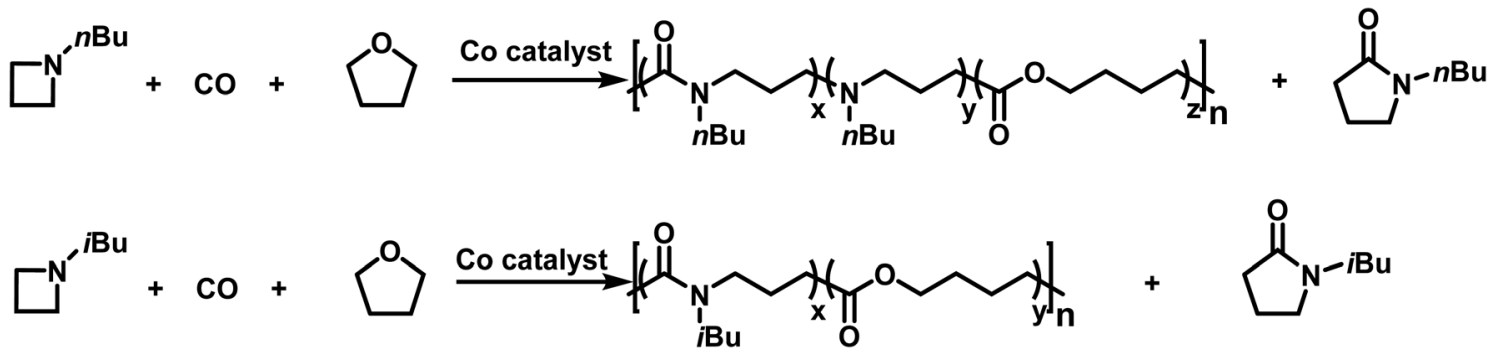

Scheme 28 Co catalyzed carbonylative polymerization of azetidine with THF to produce poly(amide-co-ester)s. ${ }^{179}$

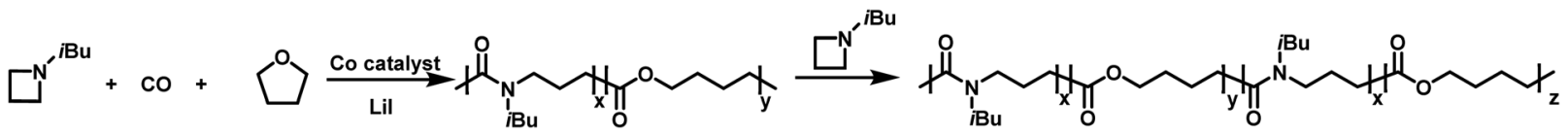

Scheme 29 Synthesis of poly(amide-co-ester) block copolymers with Lil and sequential addition of azetidine. ${ }^{180}$
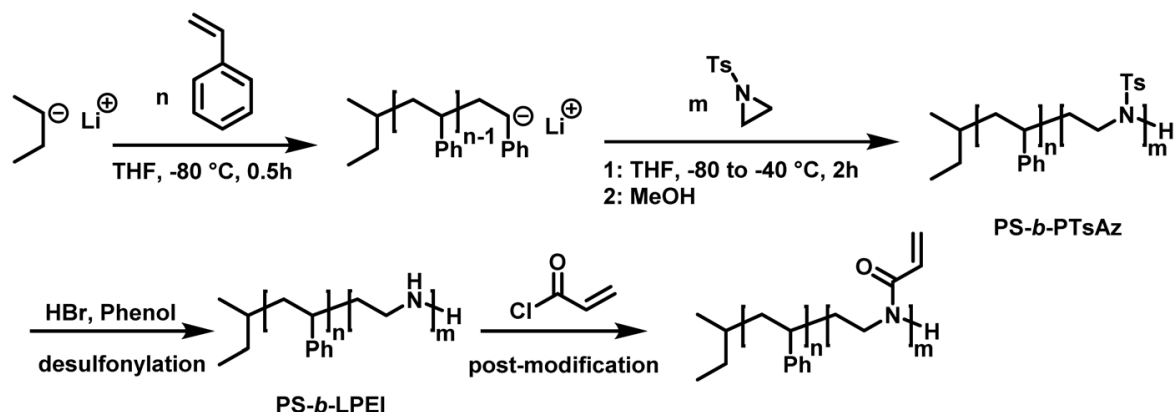

PS-b-PTsAz

PS-b-LPEI

Scheme 30 Two step synthesis of polystyrene-block-polytosylaziridine and desulfonylation to polystyrene-block-polyethylenimine. ${ }^{144}$

styrene-block-poly( $N$-tosylaziridine) by consecutive living anionic polymerization of styrene and $N$-tosyl aziridine (Scheme 30).

Quantitative transfer from the carbanions to azaanions was proven and oligomerization of the sulfonyl-activated aziridine was confirmed. Thomi et al. further demonstrated the quantitative removal of the sulfonyl groups by acidic hydrolysis with hydrobromic acid and phenol, releasing the amino groups attached to polystyrene to produce PS- $b$-LPEI. ${ }^{144}$ The introduced amine functionalities are a suitable platform for further efficient modifications which was shown by reaction with acryloyl chloride (Scheme 30). Short oligomers of the second block $(1<m<5)$ were easily obtained, but block copolymers (up to 30 repeat units TsAz) with an increasing number of TsAz needed longer reaction times, due to the insolubility which inhibits further propagation. ${ }^{144}$

Copolymers of aziridine and ethylene oxide are interesting materials for biomedical applications or as surfactants. Attempts for the cationic ring-opening copolymerization of epoxides and $N$-substituted aziridines failed. ${ }^{184}$ Very recently, the anionic copolymerization of sulfonyl aziridines and ethylene oxide was achieved (Scheme 31). ${ }^{146}$ In a single step, welldefined amphiphilic block copolymers were obtained by a one- pot copolymerization. The highest difference of reactivity ratios ever reported for an anionic copolymerization (with $r_{1}=$ 265 and $r_{2}=0.004$ for 2-methyl- $N$-tosylaziridine/EO and $r_{1}=$ 151 and $r_{2}=0.013$ for 2-methyl- $N$-mesylaziridine/EO) led to the formation of block copolymers in a closed system. The amphiphilic diblock copolymers were used as a novel class of nonionic and responsive surfactants. In addition, this unique comonomer reactivity allowed fast access to multiblock copolymers: we prepared the first amphiphilic penta- or tetrablock copolymers containing aziridines in only one or two steps, respectively. These examples render the combination of epoxide and aziridine copolymerization to be a powerful strategy to sophisticated macromolecular architectures and nanostructures.

\section{Polymer architectures}

The aziridine building block can be used to prepare threedimensional, polymer architectures. The typical polymer architectures for polyethylenimine-derivatives are, however, only hyperbranched (from CROP of aziridine) or linear (from CROP of oxazolines or AROP of sulfonyl aziridines). Few more complex copolymer architectures are reported to date. Current 


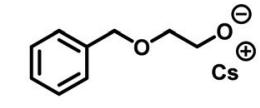

or

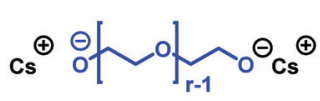

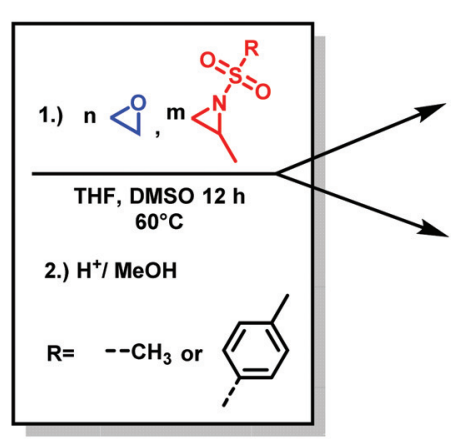
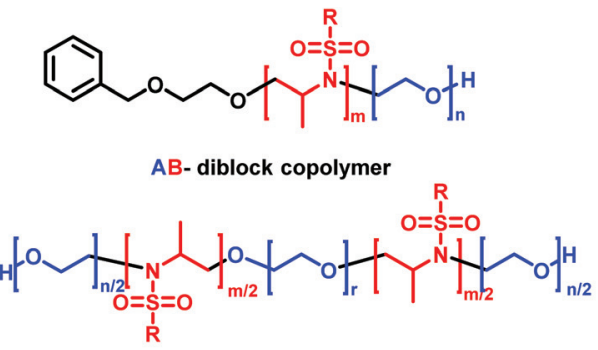

ABABA- pentablock copolymer

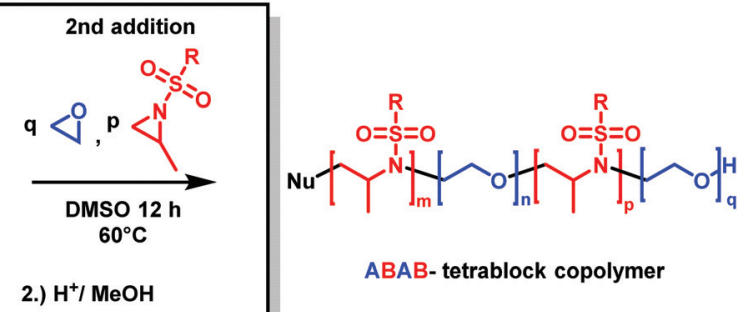

living AB- diblock copolymer

Scheme 31 Synthesis of poly(aziridine)- $b$-poly(ethylene glycol) block copolymers by anionic copolymerization (2-methyl- $N$-tosylaziridine (TsMAz), 2-methyl- $N$-mesylaziridine (MsMAz), and $N$-tosylaziridine (TsMAz) were used in this study). Top: In a single step, either AB-diblock or ABABA-pentablock copolymers can be prepared. Bottom: Sequential addition of aziridine/EO mixture produces ABAB-tetrablock copolymers. Reproduced from ref. 146 with permission from American Chemical Society, copyright 2018.

literature has studied the influence of different PEI architectures and molar masses on DNA complexation behavior, cell transfection efficiency, and toxicity. ${ }^{135,185-187}$

Various multiarm star polymers with $h b \mathrm{PEI}$ as core were synthesized (Scheme 32). The arms of shell type star-PEIs can be obtained by different synthetic strategies. ROP allows the use of $h b P E I$ as a macroinitiator to graft several different "shell-polymers" to the core. The most well known are: polyamide-12, $\varepsilon$-caprolactone, polylactide, and other polyesters. Multiarm star polymers can be afforded as well-defined nanoparticles with potential uses in nanomedicine, catalysis, and drug or gene delivery. Furthermore, star-like topologies were studied due to their unusual physical and rheological properties. These properties were found to be mainly dependant on the number of end groups, molecular weight, and the length of the arms. ${ }^{188}$

Since the polymerization of ethyleneimine was first developed by Zomlefer and co workers ${ }^{89}$ in 1943, tuning and adjust-
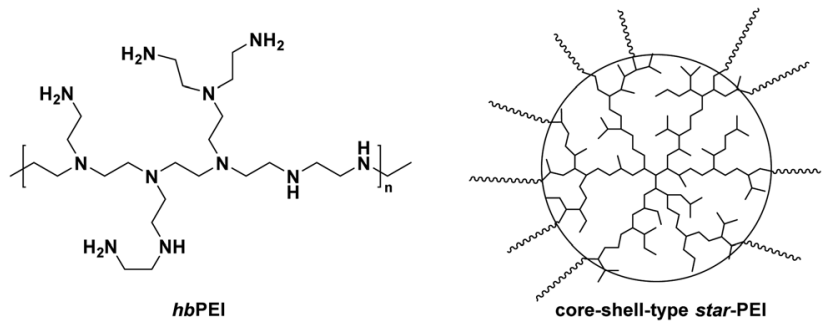

Scheme 32 Illustration of hbPEl and core shell type star-PEI. ing of the $h b \mathrm{PEI}$ architecture has been investigated. Comparing low molecular weight $h b$ PEI $\left(12 \mathrm{~kg} \mathrm{~mol}^{-1}\right)$ (LMW-PEI) and high molecular weight $h b$ PEI $\left(1600 \mathrm{~kg} \mathrm{~mol}^{-1}\right)$ (HMW-PEI) shows that the degree of branching increases with the degree of polymerization. Commercially available high molecular mass $h b$ PEI exhibits a ratio of primary: secondary: tertiary amines close to $1: 1: 1$, which indicates a very dense polymer structure with a branching unit on every second nitrogen. ${ }^{129}$ This ratio changes towards an excess of primary amines when decreasing the molecular weight; the amine ratio of this PEI, is mostly independent of molar masses from $8600-24300 \mathrm{~g} \mathrm{~mol}^{-1}$, is close to $3: 5: 2$. Commercial PEI $\left(D_{\mathrm{p}}=\right.$ 16) has an amine ratio of $\sim 4: 3: 3$. Such LMW-PEI is usually synthesized in dilute acidic aqueous environment. The less dense structure consists on average of two linear repeating units. ${ }^{129,187,189}$ Kissel and coworkers ${ }^{189}$ demonstrated, that by varying the reaction temperature from $35{ }^{\circ} \mathrm{C}$ to $100{ }^{\circ} \mathrm{C}$, the molecular weight of PEI can be adjusted from 24300 to 8610 $\mathrm{g} \mathrm{mol}^{-1}$. Though certain relationships between molar mass, synthetic route, and degree of branching are known, systematic studies of these polymers regarding their properties remain challenging due to increasing dispersities with increasing $D_{\mathrm{p}}$ caused by uncontrolled crosslinking.

Cyclic PEI (c-PEI) was first synthesized by Grayson et al. ${ }^{190}$ (Scheme 33). They used propargyl $p$-toluene-sulfonate as initiator to polymerize ethyloxazoline under anhydrous conditions. To minimize termination and chain transfer reactions caused by aqueous impurities, the polymerization was performed in a microwave reactor. Selective termination by adding sodium azide gives $\alpha$-, $\omega$-functionalized polyoxazoline. 


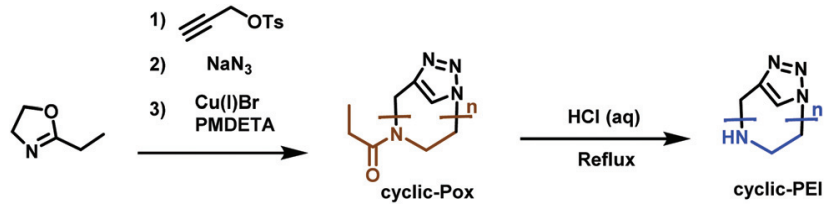

Scheme 33 Synthesis route towards C-PEI. ${ }^{190}$

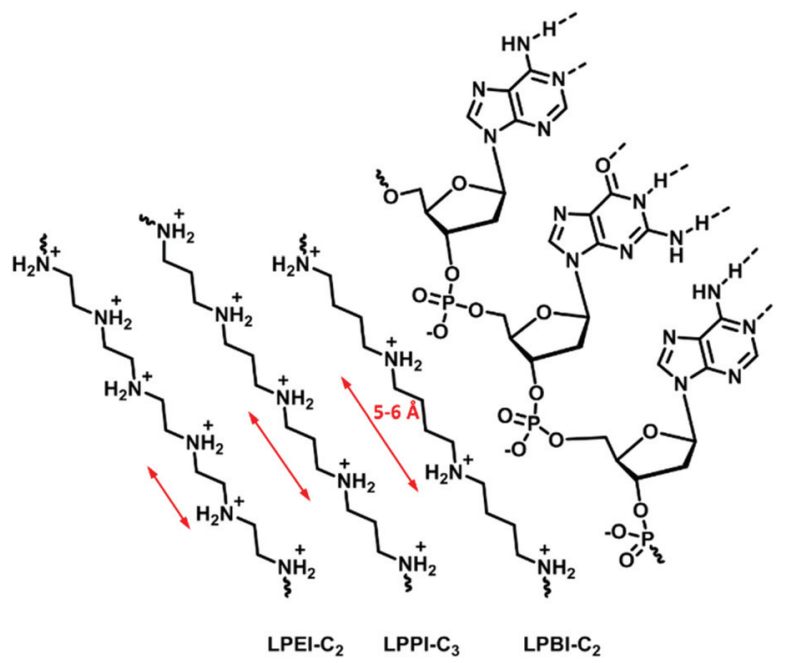

Fig. 8 Schematic representation of the nitrogen spacing in polyamine analogs and their interaction with RNA.

Subsequent click-chemistry, to cyclize the polymers, followed by acidic hydrolysis, leads to $c$-PEI. The effect of polymer structure (i.e. linear, cyclic, branched, etc.) on DNA complexation was studied and it was determined that $c$-PEI polymers showed reduced toxicity and stronger complexation. This is most likely contributed to the higher charge density compared to the linear analogue. Grayson's study precisely points out the need to develop new strategies for new PEI architectures for increased understanding in terms of their properties and potential applications.

Haag and coworkers ${ }^{191}$ investigated the influence of the length of the alkylene spacer, as an efficient complexation agent for DNA needs to optimize the number of phosphate units bound. Their study investigated the complexation behavior of ethylene, propylene, and butylene spacers synthesized with different strategies (Fig. 8). Polyamines containing a butylene spacer showed stronger DNA complexation as well as decreased cytotoxicity. It was proposed, due to calculations, that the $\mathrm{N}-\mathrm{N}$ distance aligns more precisely with the P-P distance of the DNA in polymers with a butylene spacer than in those with an ethylene spacer. Additionally, the increasing hydrophobicity likely also effects the biological properties.

\section{Conclusions}

The polymerization of aziridines (especially ethylenimine) has had industrial relevance for several decades and polyethyl- enimine is used in a wide range of applications from chelators to biomedical applications. Hyperbranched PEI is available commercially at low cost, however its molecular characteristics, molar mass, and dispersity are only poorly controlled by the industrial cationic ring-opening polymerization of ethylenimine. Due to these issues, aziridine polymerizations have been sparsely studied over the course of the last couple decades. Azetidine polymers are even more exotic in both industrial and academic polymer research.

However, with the development of the living anionic polymerization of sulfonyl aziridines and azetidines, the possibility to install well-defined polyamine building blocks in different macromolecular architectures has been achieved. However, to date, only very few of these polysulfonamides have been transformed into the respective polyamines, as the desulfonylation step is challenging and proceeds typically under harsh conditions, but some recent efforts have paved the way to feasible synthetic routes with control over molar mass and dispersity. While these polyamines contain high value, the polysulfonamides are also interesting, novel polymers that have been only scarcely characterized for their potential applications.

The development of the living polymerization of aziridineand azetidine-derivatives was a milestone to develop polymer architectures with these building blocks and will open the possibility to a plethora of future applications.

\section{Conflicts of interest}

There are no conflicts to declare.

\section{Acknowledgements}

The authors thank Katharina Maisenbacher (MPIP) for assistance with graphical design. F. R. W. thanks the Deutsche Forschungsgemeinschaft (WU 750/7-1) for funding. Open Access funding provided by the Max Planck Society.

\section{References}

1 S. Penczek, P. Kubisa and K. Matyjaszewski, Oxiranes, Springer Berlin Heidelberg, Berlin, Heidelberg, 1985.

2 G. Gee, W. C. E. Higginson, P. Levesley and K. J. Taylor, J. Chem. Soc., 1959, 1338-1344, DOI: 10.1039/ JR9590001338.

3 G. Gee, W. C. E. Higginson and G. T. Merrall, J. Chem. Soc., 1959, 1345-1352, DOI: 10.1039/JR9590001345.

4 E. H. Schacht and E. J. Goethals, Makromol. Chem., 1974, 175, 3447-3459.

5 E. J. Goethals, E. H. Schacht, P. Bruggeman and P. Bossaer, in Ring-Opening Polymerization, American Chemical Society, 1977, vol. 59, ch. 1, pp. 1-12.

6 S. Kobayashi, Prog. Polym. Sci., 1990, 15, 751-823.

7 M. Jäger, S. Schubert, S. Ochrimenko, D. Fischer and U. S. Schubert, Chem. Soc. Rev., 2012, 41, 4755-4767. 
8 M. L. Sarazen and C. W. Jones, Macromolecules, 2017, 50, 9135-9143.

9 In the literature, polytrimethylenimine (PTMI) is also called polypropylenimine (PPI). We prefer PTMI.

10 S. W. Benson, F. R. Cruickshank, D. M. Golden, G. R. Haugen, H. E. O'Neal, A. S. Rodgers, R. Shaw and R. Walsh, Chem. Rev., 1969, 69, 279-324.

11 H. K. Eigenmann, D. M. Golden and S. W. Benson, J. Phys. Chem., 1973, 77, 1687-1691.

12 T. Li, L. Wu, J. Zhang, G. Xi, Y. Pang, X. Wang and T. Chen, ACS Appl. Mater. Interfaces, 2016, 8, 3131131320.

13 J. Pan, Z. Lyu, W. Jiang, H. Wang, Q. Liu, M. Tan, L. Yuan and H. Chen, ACS Appl. Mater. Interfaces, 2014, 6, 1439114398.

14 X. Ding, W. Wang, Y. Wang, X. Bao, Y. Wang, C. Wang, J. Chen, F. Zhang and J. Zhou, Mol. Pharm., 2014, 11, 3307-3321.

15 Y.-L. Lo, K.-H. Sung, C.-C. Chiu and L.-F. Wang, Mol. Pharm., 2013, 10, 664-676.

16 M. Jaeger, S. Schubert, S. Ochrimenko, D. Fischer and U. S. Schubert, Chem. Soc. Rev., 2012, 41, 4755-4767.

17 S. C. De Smedt, J. Demeester and W. E. Hennink, Pharm. Res., 2000, 17, 113-126.

18 D. W. Pack, A. S. Hoffman, S. Pun and P. S. Stayton, Nat. Rev. Drug Discovery, 2005, 4, 581.

19 C. T. De Ilarduya, Y. Sun and N. Düzgüneş, Eur. J. Pharm. Sci., 2010, 40, 159-170.

20 M. D. Giron-Gonzalez, R. Salto-Gonzalez, F. J. LopezJaramillo, A. Salinas-Castillo, A. B. Jodar-Reyes, M. OrtegaMuñoz, F. Hernandez-Mateo and F. Santoyo-Gonzalez, Bioconjugate Chem., 2016, 27, 549-561.

21 M. A. Mintzer and E. E. Simanek, Chem. Rev., 2008, 109, 259-302.

22 M. Neu, D. Fischer and T. Kissel, J. Gene Med., 2005, 7, 992-1009.

23 C. Raymond, R. Tom, S. Perret, P. Moussouami, D. L'Abbé, G. St-Laurent and Y. Durocher, Methods, 2011, 55, 44-51.

24 E. Altuntaş, K. Knop, L. Tauhardt, K. Kempe, A. C. Crecelius, M. Jäger, M. D. Hager and U. S. Schubert, J. Mass Spectrom., 2012, 47, 105-114.

25 S. M. Moghimi, P. Symonds, J. C. Murray, A. C. Hunter, G. Debska and A. Szewczyk, Mol. Ther., 2005, 11, 990-995.

26 O. Boussif, F. Lezoualc'h, M. A. Zanta, M. D. Mergny, D. Scherman, B. Demeneix and J.-P. Behr, Proc. Natl. Acad. Sci. U. S. A., 1995, 92, 7297-7301.

27 M. Thomas and A. M. Klibanov, Proc. Natl. Acad. Sci. U. S. A., 2003, 100, 9138-9143.

28 M. S. Shim and Y. J. Kwon, Bioconjugate Chem., 2009, 20, 488-499.

29 M.-E. Bonnet, P. Erbacher and A.-L. Bolcato-Bellemin, Pharm. Res., 2008, 25, 2972.

30 L. Wightman, R. Kircheis, V. Rössler, S. Carotta, R. Ruzicka, M. Kursa and E. Wagner, J. Gene Med., 2001, 3, 362-372.
31 H. Yin, R. L. Kanasty, A. A. Eltoukhy, A. J. Vegas, J. R. Dorkin and D. G. Anderson, Nat. Rev. Genet., 2014, 15, 541 .

32 T. K. Kim and J. H. Eberwine, Anal. Bioanal. Chem., 2010, 397, 3173-3178.

33 L. Xie, Y. Tan, Z. Wang, H. Liu, N. Zhang, C. Zou, X. Liu, G. Liu, J. Lu and H. Zheng, ACS Appl. Mater. Interfaces, 2016, 8, 29261-29269.

34 H. Nguyen, P. Lemieux, S. Vinogradov, C. Gebhart, N. Guerin, G. Paradis, T. Bronich, V. Alakhov and A. Kabanov, Gene Ther., 2000, 7, 126.

35 H. Petersen, P. M. Fechner, A. L. Martin, K. Kunath, S. Stolnik, C. J. Roberts, D. Fischer, M. C. Davies and T. Kissel, Bioconjugate Chem., 2002, 13, 845-854.

36 M. Breunig, U. Lungwitz, R. Liebl and A. Goepferich, Proc. Natl. Acad. Sci. U. S. A., 2007, 104, 14454-14459.

37 N. M. Milović, J. Wang, K. Lewis and A. M. Klibanov, Biotechnol. Bioeng., 2005, 90, 715-722.

38 M. Thomas and A. M. Klibanov, Proc. Natl. Acad. Sci. U. S. A., 2002, 99, 14640-14645.

39 M. Wang, P. Lu, B. Wu, J. D. Tucker, C. Cloer and Q. Lu, J. Mater. Chem., 2012, 22, 6038-6046.

40 P. Xu, G. K. Quick and Y. Yeo, Biomaterials, 2009, 30, 5834-5843.

41 B.-K. Kim, D. Kim, G. Kwak, J. Y. Yhee, I.-C. Kwon, S. H. Kim and Y. Yeo, ACS Biomater. Sci. Eng., 2017, 3, 990-999.

42 Y. Zhou, F. Yu, F. Zhang, G. Chen, K. Wang, M. Sun, J. Li and D. Oupickỳ, Biomacromolecules, 2018, 19(2), 392-401.

43 F. Wang, L. Gao, L.-Y. Meng, J.-M. Xie, J.-W. Xiong and Y. Luo, ACS Appl. Mater. Interfaces, 2016, 8, 3352933538.

44 L. Tauhardt, K. Kempe, K. Knop, E. Altuntaș, M. Jäger, S. Schubert, D. Fischer and U. S. Schubert, Macromol. Chem. Phys., 2011, 212, 1918-1924.

45 V. P. Dhende, S. Samanta, D. M. Jones, I. R. Hardin and J. Locklin, ACS Appl. Mater. Interfaces, 2011, 3, 2830-2837.

46 J. Gao, E. M. White, Q. Liu and J. Locklin, ACS Appl. Mater. Interfaces, 2017, 9, 7745-7751.

47 J. Haldar, D. An, L. A. de Cienfuegos, J. Chen and A. M. Klibanov, Proc. Natl. Acad. Sci. U. S. A., 2006, 103, 17667-17671.

48 A. M. Bieser and J. C. Tiller, Macromol. Biosci., 2011, 11, 526-534.

49 S. A. Koplin, S. Lin and T. Domanski, Biotechnol. Prog., 2008, 24, 1160-1165.

50 R. Kügler, O. Bouloussa and F. Rondelez, Microbiology, 2005, 151, 1341-1348.

51 J. Lin, J. C. Tiller, S. B. Lee, K. Lewis and A. M. Klibanov, Biotechnol. Lett., 2002, 24, 801-805.

52 A. M. Bieser and J. C. Tiller, Macromol. Biosci., 2011, 11, 526-534.

53 S. Choi, J. H. Drese and C. W. Jones, ChemSusChem, 2009, 2, 796-854.

54 J. C. Hicks, J. H. Drese, D. J. Fauth, M. L. Gray, G. Qi and C. W. Jones, J. Am. Chem. Soc., 2008, 130, 2902-2903. 
55 P. Li, B. Ge, S. Zhang, S. Chen, Q. Zhang and Y. Zhao, Langmuir, 2008, 24, 6567-6574.

56 F.-Q. Liu, L. Wang, Z.-G. Huang, C.-Q. Li, W. Li, R.-X. Li and W.-H. Li, ACS Appl. Mater. Interfaces, 2014, 6, 43714381.

57 Q. Wang, J. Luo, Z. Zhong and A. Borgna, Energy Environ. Sci., 2011, 4, 42-55.

58 X. Xu, C. Song, B. G. Miller and A. W. Scaroni, Fuel Process. Technol., 2005, 86, 1457-1472.

59 W. Chaikittisilp, R. Khunsupat, T. T. Chen and C. W. Jones, Ind. Eng. Chem. Res., 2011, 50, 1420314210.

60 N. MacDowell, N. Florin, A. Buchard, J. Hallett, A. Galindo, G. Jackson, C. S. Adjiman, C. K. Williams, N. Shah and P. Fennell, Energy Environ. Sci., 2010, 3, 1645-1669.

61 R. Sanz, G. Calleja, A. Arencibia and E. S. Sanz-Pérez, J. Mater. Chem. A, 2013, 1, 1956-1962.

62 X. Xu, C. Song, J. M. Andresen, B. G. Miller and A. W. Scaroni, Energy Fuels, 2002, 16, 1463-1469.

63 S. Satyapal, T. Filburn, J. Trela and J. Strange, Energy Fuels, 2001, 15, 250-255.

64 E. Bayer, B. Y. Spivakov and K. Geckeler, Polym. Bull., 1985, 13, 307-311.

65 S. Kobayashi, K. Hiroishi, M. Tokunoh and T. Saegusa, Macromolecules, 1987, 20, 1496-1500.

66 A. Von Zelewsky, L. Barbosa and C. Schläpfer, Coord. Chem. Rev., 1993, 123, 229-246.

67 B. A. Bolto, Prog. Polym. Sci., 1995, 20, 987-1041.

68 H.-C. Chen, S.-W. Lin, J.-M. Jiang, Y.-W. Su and K.-H. Wei, ACS Appl. Mater. Interfaces, 2015, 7, 6273-6281.

69 S. Stolz, Y. Zhang, U. Lemmer, G. Hernandez-Sosa and H. Aziz, ACS Appl. Mater. Interfaces, 2017, 9, 2776-2785.

70 G. F. Zou, J. Zhao, H. M. Luo, T. M. McCleskey, A. K. Burrell and Q. X. Jia, Chem. Soc. Rev., 2013, 42, 439449.

71 https://www.chempoint.com/products/basf/lupasolpolyethylenimine-adhesion-promoters/lupasolpolyethylenimine.

72 U. Steuerle and R. Feuerhake, Ullmann's Encyclopedia of Industrial Chemistry, 2001.

73 J. B. Sweeney, Chem. Soc. Rev., 2002, 31, 247-258.

74 J. Herzberger, K. Niederer, H. Pohlit, J. Seiwert, M. Worm, F. R. Wurm and H. Frey, Chem. Rev., 2016, 116, 21702243.

75 B. D. Monnery and R. Hoogenboom, Cationic Polymers in Regenerative Medicine, 2014, pp. 30-61.

76 D. A. Tomalia and D. P. Sheetz, J. Polym. Sci., Part A-1: Polym. Chem., 1966, 4, 2253-2265.

77 W. Seeliger, E. Aufderhaar, W. Diepers, R. Feinauer, R. Nehring, W. Thier and H. Hellmann, Angew. Chem., Int. Ed. Engl., 1966, 5, 875-888.

78 T. Kagiya, S. Narisawa, T. Maeda and K. Fukui, J. Polym. Sci., Part B: Polym. Lett., 1966, 4, 441-445.

79 R. Tanaka, I. Ueoka, Y. Takaki, K. Kataoka and S. Saito, Macromolecules, 1983, 16, 849-853.
80 H. M. L. Lambermont-Thijs, F. S. van der Woerdt, A. Baumgaertel, L. Bonami, F. E. Du Prez, U. S. Schubert and R. Hoogenboom, Macromolecules, 2009, 43, 927-933.

81 T. Saegusa, A. Yamada, H. Taoda and S. Kobayashi, Macromolecules, 1978, 11, 435-436.

82 E. Rieger, T. Gleede, A. Manhart, M. Lamla and F. R. Wurm, ACS Macro Lett., 2018, 7, 598-603.

83 L. Reisman, C. P. Mbarushimana, S. J. Cassidy and P. A. Rupar, ACS Macro Lett., 2016, 5, 1137-1140.

84 H. Yin, R. L. Kanasty, A. A. Eltoukhy, A. J. Vegas, J. R. Dorkin and D. G. Anderson, Nat. Rev. Genet., 2014, 15, 541 .

85 P. Wilson, P. C. Ke, T. P. Davis and K. Kempe, Eur. Polym. J., 2017, 88, 486-515.

86 L. Tauhardt, K. Kempe, M. Gottschaldt and U. S. Schubert, Chem. Soc. Rev., 2013, 42, 7998-8011.

87 M. A. Mees and R. Hoogenboom, Polym. Chem., 2018, 9, 4968-4978.

88 J. Y. Johnson and G. W. Johnson, Great Britain Pat., GB461666 (A), 1937.

89 G. D. Jones, A. Langsjoen, S. M. M. C. Neumann and J. Zomlefer, J. Org. Chem., 1944, 09(2), 125-147.

90 D. R. Holycross and M. Chai, Macromolecules, 2013, 46, 6891-6897.

91 W. G. Barb, J. Chem. Soc., 1955, 2564-2577, DOI: 10.1039/ JR9550002564.

92 B. L. Rivas and B. Barría, Polym. Bull., 1996, 36, 157164.

93 T. Toshikazu, Y. Z. Menceloglu and E. Takeshi, J. Polym. Sci., Part A: Polym. Chem., 1992, 30, 501-504.

94 M. Bakloutl, R. Chaabouni, J. Sledz and F. Schué, Polym. Bull., 1989, 21, 243-250.

95 J. Xu, X. Li and N. Chen, Synthesis, 2010, 3423-3428.

96 J. A. Deyrup, in The Chemistry of Heterocyclic Compounds, Part 1, ed. A. Hassner, Wiley, New York, 1983, vol. 42, pp. 1-214.

97 E. Goethals, E. Schacht, P. Bruggeman and P. Bossaer, Cationic Polymerization of Cyclic Amines, ACS Publications, 1977, vol. 59, DOI: 10.1021/bk-1977-0059.ch001.

98 C. R. Dick, J. Org. Chem., 1967, 32, 72-75.

99 K. F. Weyts and E. J. Goethals, Polym. Bull., 1988, 19, 1319.

100 J. J. Jakubowski and R. V. Subramanian, Polymer, 1980, 21, 230-232.

101 K. E. Geckeler, B. L. Rivas and R. Zhou, Angew. Makromol. Chem., 1991, 193, 195-203.

102 S. A. Pooley, G. S. Canessa and B. L. Rivas, Macromol. Chem. Phys., 1998, 199, 2293-2299.

103 B. L. Rivas, G. S. Canessa and S. A. Pooley, Makromol. Chem., Rapid Commun., 1987, 8, 365-372.

104 S. A. Pooley, G. S. Canessa, B. L. Rivas and E. Espejo, Polym. Bull., 1995, 35, 271-277.

105 S. A. Pooley, G. S. Canessa, B. L. Rivas and E. Espejo, Polym. Bull., 1996, 36, 415-422.

106 S. A. Pooley, G. S. Canessa, B. L. Rivas and E. Espejo, Polym. Bull., 1997, 39, 407-414. 
107 S. A. Pooley, G. S. Canessa, B. L. Rivas and E. Espejo, Bol. Soc. Chil. Quim., 1996, 41, 261-270.

108 S. A. Pooley, G. S. Canessa, B. L. Rivas and E. Espejo, Bol. Soc. Chil. Quim., 1994, 39, 305-313.

109 S. A. Pooley, G. S. Canessa, B. L. Rivas and E. Espejo, Bol. Soc. Chil. Quim., 1996, 41, 71-78.

1101967.

111 S. Hashimoto and T. Yamashita, J. Macromol. Sci., Chem., 1986, 23, 295-304.

112 S. Hashimoto, T. Yamashita and J. Hino, Polym. J., 1977, 9, 19.

113 E. R. Lavagnino, R. R. Chauvette, W. N. Cannon and E. C. Kornfeld, J. Am. Chem. Soc., 1960, 82, 2609-2613.

114 H. Oike, M. Washizuka and Y. Tezuka, Macromol. Chem. Phys., 2000, 201, 1673-1678.

115 E. H. Schacht and E. J. Goethals, Makromol. Chem., 1973, 167, 155-169.

116 E. J. Goethals and B. Dervaux, in Polymer Science: A Comprehensive Reference, ed. M. Möller, Elsevier, Amsterdam, 2012, pp. 309-330, DOI: 10.1016/B978-0-44453349-4.00108-4.

117 E. J. Goethals, E. H. Schacht, Y. E. Bogaert, S. I. Ali and Y. Tezuka, Polym. J., 1980, 12, 571.

118 T. Saegusa and E. Goethals, Ring-Opening Polymerization, American Chemical Society, 1977.

119 A. T. Bottini and J. D. Roberts, J. Am. Chem. Soc., 1958, 80, 5203-5208.

120 H. K. Hall, J. Am. Chem. Soc., 1957, 79, 5441-5444.

121 S. Penczek and P. Kubisa, Makromol. Chem., 1969, 130, 186-209.

122 E. J. Goethals, G. G. Trossaert, P. J. Hartmann and K. Engelen, Makromol. Chem., Macromol. Symp., 1993, 73, 77-89.

123 E. J. Goethals, E. Schacht and D. Tack, J. Polym. Sci., Part A-1: Polym. Chem., 1972, 10, 533-539.

124 I. C. Stewart, C. C. Lee, R. G. Bergman and F. D. Toste, J. Am. Chem. Soc., 2005, 127, 17616-17617.

125 Z. Wang, Comprehensive Organic Name Reactions and Reagents, John Wiley \& Sons, Inc., 2009, vol. 3, ISBN: 9780-471-70450-8.

126 H. Xu, H. Tian, L. Zheng, Q. Liu, L. Wang and S. Zhang, Tetrahedron Lett., 2011, 52, 2873-2875.

127 M. B. Berry and D. Craig, Synlett, 1992, 41-44.

128 A. J. Catino, J. M. Nichols, R. E. Forslund and M. P. Doyle, Org. Lett., 2005, 7, 2787-2790.

129 A. V. Gontcharov, H. Liu and K. B. Sharpless, Org. Lett., 1999, 1, 783-786.

130 J. U. Jeong, B. Tao, I. Sagasser, H. Henniges and K. B. Sharpless, J. Am. Chem. Soc., 1998, 120, 6844-6845.

131 E. Rieger, A. Alkan, A. Manhart, M. Wagner and F. R. Wurm, Macromol. Rapid Commun., 2016, 37, 833839.

132 E. Rieger, A. Manhart and F. R. Wurm, ACS Macro Lett., 2016, 5, 195-198.

133 L. Thomi and F. R. Wurm, Macromol. Symp., 2015, 349, 51-56.
134 P. O'Brien and J. Huang, Synthesis, 2006, 425-434, DOI: 10.1055/s-2006-926282.

135 Y. Zhao, F. Sakai, L. Su, Y. Liu, K. Wei, G. Chen and M. Jiang, Adv. Mater., 2013, 25, 5215-5256.

136 E. Rieger, J. Blankenburg, E. Grune, M. Wagner, K. Landfester and F. R. Wurm, Angew. Chem., Int. Ed., 2018, 57, 2483-2487.

137 T. Gleede, E. Rieger, T. Homann-Müller and F. R. Wurm, Macromol. Chem. Phys., 2017, 1700145, DOI: 10.1002/ macp. 201700145.

138 X. Wang, Y. Liu, Z. Li, H. Wang, H. Gebru, S. Chen, H. Zhu, F. Wei and K. Guo, ACS Macro Lett., 2017, 6, 13311336.

139 T. Gleede, E. Rieger, L. Liu, C. Bakkali-Hassani, M. Wagner, S. Carlotti, D. Taton, D. Andrienko and F. R. Wurm, Macromolecules, 2018, 51, 5713-5719.

140 T. Homann-Müller, E. Rieger, A. Alkan and F. R. Wurm, Polym. Chem., 2016, 7, 5501-5506.

141 P. C. Mbarushimana, Q. Liang, J. M. Allred and P. A. Rupar, Macromolecules, 2018, 51(3), 977-983.

142 L. Reisman, E. A. Rowe, Q. Liang and P. A. Rupar, Polym. Chem., 2018, 9, 1618-1625.

143 E. Rieger, T. Gleede, K. Weber, A. Manhart, M. Wagner and F. R. Wurm, Polym. Chem., 2017, 8, 2824-2832.

144 L. Thomi and F. R. Wurm, Macromol. Rapid Commun., 2014, 35, 585-589.

145 C. Bakkali-Hassani, E. Rieger, J. Vignolle, F. R. Wurm, S. Carlotti and D. Taton, Eur. Polym. J., 2017, 95, 746755.

146 T. Gleede, E. Rieger, J. Blankenburg, K. Klein and F. R. Wurm, J. Am. Chem. Soc., 2018, 140, 13407-13412.

147 C. Bakkali-Hassani, E. Rieger, J. Vignolle, F. R. Wurm, S. Carlotti and D. Taton, Chem. Commun., 2016, 52, 97199722.

148 C. Bakkali-Hassani, C. Coutouly, T. Gleede, J. Vignolle, F. R. Wurm, S. Carlotti and D. Taton, Macromolecules, 2018, 51, 2533-2541.

149 E. Rieger, T. Gleede, K. Weber, A. Manhart, M. Wagner and F. R. Wurm, Polym. Chem., 2017, 8, 2824-2832.

150 V. Jaacks, Angew. Chem., 1967, 79, 419.

151 F. T. Wall, J. Am. Chem. Soc., 1941, 63, 1862-1866.

152 J. Blankenburg, M. Wagner and H. Frey, Macromolecules, 2017, 50, 8885-8893.

153 D. C. McLeod and N. V. Tsarevsky, Macromol. Rapid Commun., 2016, 37, 1694-1700.

154 H.-J. Jang, J. T. Lee and H. J. Yoon, Polym. Chem., 2015, 6, 3387-3391.

155 H. K. Moon, S. Kang and H. J. Yoon, Polym. Chem., 2017, 8, 2287-2291.

156 T. Suzuki, J.-i. Kusakabe, K. Kitazawa, T. Nakagawa, S. Kawauchi and T. Ishizone, Macromolecules, 2010, 43, 107-116.

157 A. Thomas, S. S. Muller and H. Frey, Biomacromolecules, 2014, 15, 1935-1954.

158 A. Alkan, R. Klein, S. I. Shylin, U. Kemmer-Jonas, H. Frey and F. R. Wurm, Polym. Chem., 2015, 6, 7112-7118. 
159 L. Reisman, E. A. Rowe, E. M. Jackson, C. Thomas, T. Simone and P. A. Rupar, J. Am. Chem. Soc., 2018, 140, 15626-15630.

160 M. K. Kiesewetter, E. J. Shin, J. L. Hedrick and R. M. Waymouth, Macromolecules, 2010, 43, 2093-2107.

161 S. Naumann and A. P. Dove, Polym. Chem., 2015, 6, 31853200.

162 J. Pinaud, K. Vijayakrishna, D. Taton and Y. Gnanou, Macromolecules, 2009, 42, 4932-4936.

163 J. Raynaud, Y. Gnanou and D. Taton, Macromolecules, 2009, 42, 5996-6005.

164 J. Raynaud, C. Absalon, Y. Gnanou and D. Taton, J. Am. Chem. Soc., 2009, 131, 3201-3209.

165 I. Perevyazko, A. S. Gubarev, L. Tauhardt, A. Dobrodumov, G. M. Pavlov and U. S. Schubert, Polym. Chem., 2017, 8, 7169-7179.

166 A. Akinc, M. Thomas, A. M. Klibanov and R. Langer, J. Gene Med., 2005, 7, 657-663.

167 S. Taranejoo, J. Liu, P. Verma and K. Hourigan, J. Appl. Polym. Sci., 2015, 132, 42096.

168 K. Aoi and M. Okada, Prog. Polym. Sci., 1996, 21, 151-208.

169 L. Tauhardt, K. Kempe, K. Knop, E. Altuntaş, M. Jäger, S. Schubert, D. Fischer and U. S. Schubert, Macromol. Chem. Phys., 2011, 212, 1918-1924.

170 D. A. Alonso and P. G. Andersson, J. Org. Chem., 1998, 63, 9455-9461.

171 H. Senboku, K. Nakahara, T. Fukuhara and S. Hara, Tetrahedron Lett., 2010, 51, 435-438.

172 I. V. Kubrakova, A. A. Formanovsky and I. V. Mikhura, Mendeleev Commun., 1999, 9, 65-66.

173 O. Ihata, Y. Kayaki and T. Ikariya, Macromolecules, 2005, 38, 6429-6434.

174 O. Ihata, Y. Kayaki and T. Ikariya, Angew. Chem., Int. Ed., 2004, 43, 717-719.

175 L. Jia, E. Ding and W. R. Anderson, Chem. Commun., 2001, 1436-1437, DOI: 10.1039/B103899K.

176 J. Zhao, E. Ding, A. M. Allgeier and L. Jia, J. Polym. Sci., Part A: Polym. Chem., 2003, 41, 376-385.
177 L. Jia, H. Sun, J. T. Shay, A. M. Allgeier and S. D. Hanton, J. Am. Chem. Soc., 2002, 124, 7282-7283.

178 D. J. Darensbourg, A. L. Phelps, N. L. Gall and L. Jia, J. Am. Chem. Soc., 2004, 126, 13808-13815.

179 G. Liu and L. Jia, Angew. Chem., Int. Ed., 2006, 45, 129131.

180 H. Sekiguchi, P. Tsourkas, F. Carriere and R. Audebert, Eur. Polym. J., 1974, 10, 1185-1193.

181 Due to this finding, $N$-isopropylazetidine was used throughout the study.

182 G. Liu and L. Jia, J. Am. Chem. Soc., 2004, 126, 1471614717.

183 H. Xu, N. LeGall, L. Jia, W. W. Brennessel and B. E. Kucera, J. Organomet. Chem., 2005, 690, 51505158.

184 C. G. Overberger and M. Tobkes, J. Polym. Sci., 1964, 2, 2181-2187.

185 A. Hall, L. Parhamifar, M. K. Lange, K. D. Meyle, M. Sanderhoff, H. Andersen, M. Roursgaard, A. K. Larsen, P. B. Jensen, C. Christensen, J. Bartek and S. M. Moghimi, Biochim. Biophys. Acta, Bioenerg., 2015, 1847, 328342.

186 B. R. Twaites, C. de las Heras Alarcón, D. Cunliffe, M. Lavigne, S. Pennadam, J. R. Smith, D. C. Górecki and C. Alexander, J. Controlled Release, 2004, 97, 551-566.

187 D. Fischer, T. Bieber, Y. Li, H.-P. Elsässer and T. Kissel, Pharm. Res., 1999, 16, 1273-1279.

188 B. W. Tylkowski, K. Wieszczycka and R. Jastrzab, Polymer Engineering, De Gruyter, 2017, ISBN 978-3-11-046828-1.

189 A. von Harpe, H. Petersen, Y. Li and T. Kissel, J. Controlled Release, 2000, 69, 309-322.

190 M. A. Cortez, W. T. Godbey, Y. Fang, M. E. Payne, B. J. Cafferty, K. A. Kosakowska and S. M. Grayson, J. Am. Chem. Soc., 2015, 137, 6541-6549.

191 W. Fischer, B. Brissault, S. Prévost, M. Kopaczynska, I. Andreou, A. Janosch, M. Gradzielski and R. Haag, Macromol. Biosci., 2010, 10, 1073-1083. 